\title{
Kinematics and Dynamics of Planar Mechanisms Reinterpreted in Rigid-Body's Configuration Space
}

\author{
Raffaele Di Gregorio \\ Department of Engineering - University of Ferrara, Via Saragat n. 1, 44122 Ferrara, Italy \\ e-mail: raffaele.digregorio@unife.it; Phone: +390532974828; Fax: +390532974870
}

\begin{abstract}
Mechanisms with lower mobility can be studied by using tools that are directly deduced from those of spatial kinematics as screw theory. Nevertheless, ad-hoc tools that fully exploit the peculiarities of the displacement subgroups these mechanisms move in are usually more efficient both in showing mechanisms' features and when used to conceive numerical algorithms. Planar displacements constitute a three-dimensional subgroup with many peculiarities that allow the use of simplified tools (e.g., complex numbers) for studying planar mechanisms. Here, the systematic use of three-dimensional vector spaces to represent link poses and velocities in planar motion and planar system of forces is investigated. The result is a novel coherent set of tools that make it possible to geometrically describe kinematics and dynamics of planar mechanisms in the three-dimensional configuration space of links' planar poses. The effectiveness of this novel approach is shown through a case study.
\end{abstract}

Keywords: Displacement group, planar displacements, planar mechanisms, configuration space.

\section{Introduction}

Mechanics of planar mechanisms [1] is usually studied in the Euclidean plane, $E^{2}$, since the elements (planar displacements) of the special Euclidean group $\mathrm{SE}(2)$ can be easily represented through point or directed-line displacements lying on the motion plane [2, 3, 4]. Actually, such displacements can be described with simple tools in $\mathrm{E}^{2}$, for instance, bi-dimensional vectors or complex numbers [1] are commonly employed.

Nevertheless, tools that are directly deduced from spatial kinematics are also used and concepts like planar wrench, planar twist and Clifford algebra of $\mathrm{E}^{2}$ are well established in the literature [2, 3, 5]. Even though these tools are able to elegantly reinterpret traditional graphical techniques $[2,6]$, they still keep some drawbacks [5] coming from their six-dimensional origin. Thus, these adapted tools should be reformulated to make them as simple as the most commonly used. 
In planar motion, rigid-body's (link's) configuration space (c-space) is three-dimensional [2] since only the two coordinates of one point and the slope angle of one directed line are sufficient to individuate the link pose. These three generalized coordinates (pose coordinates) would suggest representing the link as a point of a three-dimensional Cartesian diagram whose xy-coordinate plane is the motion plane, that is, $\mathrm{E}^{2}$, and whose $\mathrm{z}$ axis gives both the positive direction of the rotation axis and the slope angle in the range $]-\pi, \pi]$ rad. This Cartesian representation has the drawback that the pose coordinates are not homogeneous. Thus, the Euclidean metric cannot be employed to measure the distance between two cspace points and alternative metrics must be defined $[7,8,9]$. Despite this, such representation can fully exploit the fact that, in $\mathrm{SE}(2)$, rotations commute and the signed magnitude of link's angular velocity is the time derivative of the slope angle (i.e., the same as the components of point's velocity are the time derivatives of the point coordinates).

This paper investigates the potentiality of the c-space of link's planar pose till to deduce the motion laws of the c-space point. In particular, the systematic use of three-dimensional vector spaces is adopted to represent link poses and velocities in planar motion and planar system of forces. Some concepts, usually deduced from spatial kinematics, are autonomously redefined and reinterpreted to make them a coherent set of simple tools that geometrically describe kinematics and dynamics of planar mechanisms in the c-space.

The paper is organized as follows. Section 2 reviews the concept of planar wrench; then, section 3 analyzes the c-space finite and instantaneous kinematics and introduces a three-dimensional vector (poserate vector) which somehow is a redefinition and a reinterpretation of the planar twist. Section 4 states the motion laws of the c-space point. Eventually, section 5 presents a case study and section 6 draws the conclusions.

\section{Planar Wrenches}

Figure 1 shows a planar force $\mathbf{f}\left[=\mathrm{f}_{\mathrm{x}} \mathbf{i}+\mathrm{f}_{\mathrm{y}} \mathbf{j}=\mathrm{f} \mathbf{n}=\mathrm{f}(\cos \theta \mathbf{i}+\sin \theta \mathbf{j})\right]$ applied to $\mathrm{P}$ and its equivalent system of forces reduced to point A. In Fig. $1, f$ is the magnitude of $\mathbf{f}$. The positive direction of $\zeta$ is given by a $90^{\circ}$ counterclockwise rotation of the unit vector $\mathbf{n}(\equiv \cos \theta \mathbf{i}+\sin \theta \mathbf{j})$ and, according to the position of $\mathrm{A}$ with respect to the line of action of $\mathbf{f}, \zeta_{\mathrm{PA}}$ can be positive, null or negative. Also, $\mathrm{m}_{\mathrm{A}} \mathbf{k}=(\mathbf{P}-\mathbf{A}) \times \mathbf{f}$ and the following relationships hold 
$(\mathbf{P}-\mathbf{A})=\left(\mathrm{x}_{\mathrm{P}}-\mathrm{x}_{\mathrm{A}}\right) \mathbf{i}+\left(\mathrm{y}_{\mathrm{P}}-\mathrm{y}_{\mathrm{A}}\right) \mathbf{j}$

$\mathrm{m}_{\mathrm{A}} \mathbf{k}=\mathrm{f}\left[\left(\mathrm{x}_{\mathrm{P}}-\mathrm{x}_{\mathrm{A}}\right) \sin \theta-\left(\mathrm{y}_{\mathrm{P}}-\mathrm{y}_{\mathrm{A}}\right) \cos \theta\right]=\mathrm{f} \zeta_{\mathrm{PA}} \mathbf{k}$

$\zeta_{\mathrm{PA}}=\left(\mathrm{x}_{\mathrm{P}}-\mathrm{x}_{\mathrm{A}}\right) \sin \theta-\left(\mathrm{y}_{\mathrm{P}}-\mathrm{y}_{\mathrm{A}}\right) \cos \theta$

With these notations, a planar force system with central axis passing through $\mathrm{P}$, when reduced to point A, can be represented by the following three-dimensional vector, $\$_{\mathrm{A}}$, (planar wrench about point $\mathrm{A}$ ) with non-homogeneous components ${ }^{1}$

$\mathbf{\$}_{\mathrm{A}}=\mathrm{f}_{\mathrm{x}} \mathbf{i}+\mathrm{f}_{\mathrm{y}} \mathbf{j}+\mathrm{m}_{\mathrm{A}} \mathbf{k}=\mathrm{f}\left(\cos \theta \mathbf{i}+\sin \theta \mathbf{j}+\zeta_{\mathrm{PA}} \mathbf{k}\right)$

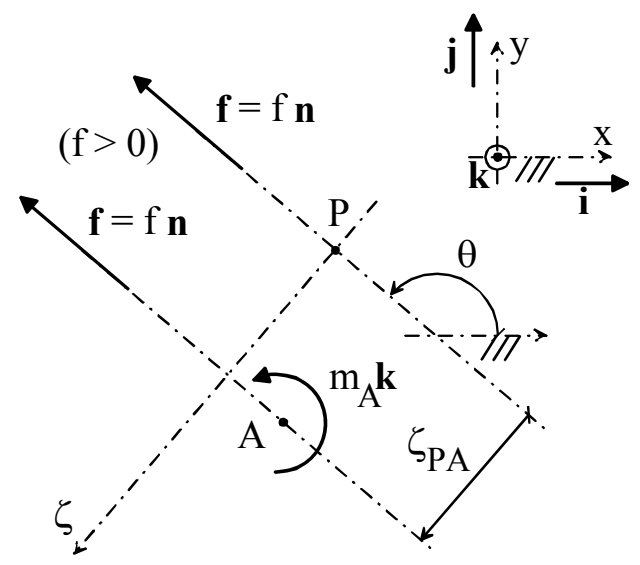

Figure 1: Planar force $f$ applied to $P$ and its equivalent system of forces reduced to point $A: i, j$ and $k$ are the unit vectors of a right-handed Cartesian system; $f$ is the magnitude of $f$; the positive direction of $\zeta$ is given by a $90^{\circ}$ counterclockwise rotation of the unit vector $n(\equiv \cos \theta i+\sin \theta j)$; according to the position of $A$ with respect to the line of action of $f, \zeta_{\mathrm{PA}}$ can be positive, null or negative.

Also, the moments transport theorem $\left[\mathrm{m}_{\mathrm{B}} \mathbf{k}=\mathrm{m}_{\mathrm{A}} \mathbf{k}+(\mathbf{A}-\mathbf{B}) \times \mathbf{f}\right]$ yields the following relationship (planar wrench's transport formula) between $\mathbf{S}_{\mathrm{A}}$ and the planar wrench, $\mathbf{\$}_{\mathrm{B}}$, about another point, B, [(A-B) $\left.=\left(\mathrm{x}_{\mathrm{A}}-\mathrm{x}_{\mathrm{B}}\right) \mathbf{i}+\left(\mathrm{y}_{\mathrm{A}}-\mathrm{y}_{\mathrm{B}}\right) \mathbf{j}\right]$

$\boldsymbol{\$}_{\mathrm{B}}=\boldsymbol{\$}_{\mathrm{A}}+\mathrm{f}\left[\left(\mathrm{x}_{\mathrm{A}}-\mathrm{x}_{\mathrm{B}}\right) \sin \theta-\left(\mathrm{y}_{\mathrm{A}}-\mathrm{y}_{\mathrm{B}}\right) \sin \theta\right] \mathbf{k} \equiv \boldsymbol{\$}_{\mathrm{A}}+\mathrm{f} \zeta_{\mathrm{AB}} \mathbf{k}$

where $\zeta_{\mathrm{AB}}=\left(\mathrm{x}_{\mathrm{A}}-\mathrm{x}_{\mathrm{B}}\right) \sin \theta-\left(\mathrm{y}_{\mathrm{A}}-\mathrm{y}_{\mathrm{B}}\right) \sin \theta$.

The rules that states the equivalence of two planar force systems [10] bring to conclude that

- the vector sum of two planar wrenches about point $A$, say $\$_{A}{ }^{(1)}$ and $\$_{A}{ }^{(2)}$, is the planar wrench about point $A$, say $\$_{A}{ }^{(3)}$, that represents the force system obtained by the union of the two force systems represented by $\mathbf{\$}_{\mathrm{A}}^{(1)}$ and $\mathbf{\$}_{\mathrm{A}}{ }^{(2)}$;

${ }^{1}$ Here, the non-homogeneity is not a problem since these components will be always separately summed. 
- the product of $\$_{\mathrm{A}}$ (Fig. 1) by a real number, say $\lambda$, is the planar wrench that represents the force $\lambda \mathbf{f}$ passing through $\mathrm{P}$.

Therefore, the set of planar wrenches about point $\mathrm{A},\left\{\boldsymbol{S}_{\mathrm{A}}{ }^{(\mathrm{i})}\right\}$, together with the two above-defined operations of vector addition and scalar multiplication is a vector space over the real numbers. The pure moments, $\boldsymbol{\kappa}_{\mathrm{A}}=\mathrm{m}_{\mathrm{A}} \mathbf{k}$, are elements of $\left\{\boldsymbol{S}_{\mathrm{A}}{ }^{(\mathrm{i})}\right\}$ that are obtained by summing two planar wrenches which represents two equal, opposite and not-aligned forces.

With reference to Fig. 1, the unit planar wrench about point $\mathrm{A}, \sigma_{\mathrm{A}}$, is defined as follows

$\sigma_{\mathrm{A}}=\cos \theta \mathbf{i}+\sin \theta \mathbf{j}+\zeta_{\mathrm{PA}} \mathbf{k}$

where $\zeta_{\mathrm{PA}}\left[\equiv\left(\mathrm{x}_{\mathrm{P}}-\mathrm{x}_{\mathrm{A}}\right) \sin \theta-\left(\mathrm{y}_{\mathrm{P}}-\mathrm{y}_{\mathrm{A}}\right) \cos \theta\right]$ is the signed distance of point $\mathrm{A}$ from the directed line with the direction of $\mathbf{n}$ and passing through P. $\sigma_{\mathrm{A}}$ uniquely identifies a directed line of the plane. It is worth noting that Eq. 4 individuates the elements of a continuous bi-dimensional set.

Even though the components of $\sigma_{\mathrm{A}}$ are not homogeneous, the mixed product $\sigma_{\mathrm{A} \mid 1} \cdot \sigma_{\mathrm{A} \mid 2} \times \sigma_{\mathrm{A} \mid 3}$ of three unit planar wrenches yields the sum of three homogeneous terms which are all lengths ${ }^{2}$. Therefore, a sum of planar wrenches can always be dot multiplied by a cross product of two unit planar wrenches.

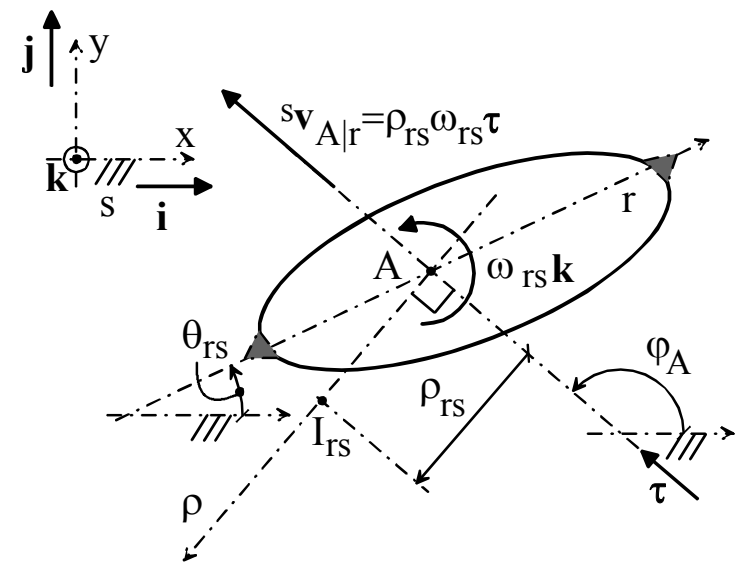

Figure 2: Pose and velocities of link $r$ with respect to the frame (link s): $I_{\mathrm{rs}}$ and $\omega_{\mathrm{rs}} \mathrm{are}$ the instant center and the angular velocity; the positive direction of $\rho$ is given by a $90^{\circ}$ counterclockwise rotation of the unit vector $\tau$ $\left(\equiv \mathbf{i} \cos \varphi_{A}+\mathbf{j} \sin \varphi_{A}\right)$, tangent to the path of point $\mathbf{A} ;{ }^{\mathbf{s}} \mathbf{v}_{\mathbf{A}} \mid \mathbf{r}\left[=\omega_{\mathrm{rs}} \mathbf{k} \times\left(\mathbf{A}-\mathbf{I}_{\mathrm{rs}}\right) \equiv \omega_{\mathrm{rs}} \rho_{\mathrm{rs}} \tau\right]$ is the velocity of point $\mathbf{A}$.

\footnotetext{
2 If $\quad \sigma_{\mathrm{A} \mid 1}=\cos \theta_{1} \mathbf{i}+\sin \theta_{1} \mathbf{j}+\zeta_{\mathrm{PA} \mid} \mathbf{k}, \quad \sigma_{\mathrm{A} \mid 2}=\cos \theta_{2} \mathbf{i}+\sin \theta_{2} \mathbf{j}+\zeta_{\mathrm{PA} \mid 2} \mathbf{k} \quad$ and $\quad \sigma_{\mathrm{A} \mid 3}=\cos \theta_{3} \mathbf{i}+\sin \theta_{3} \mathbf{j}+\zeta_{\mathrm{PA} \mid 3} \mathbf{k}$, then $\sigma_{\mathrm{A} \mid 1} \cdot \boldsymbol{\sigma}_{\mathrm{A} \mid 2} \times \boldsymbol{\sigma}_{\mathrm{A} \mid 3}=\zeta_{\mathrm{PA} \mid} \sin \left(\theta_{3}-\theta_{2}\right)+$ $\zeta_{\mathrm{PA} \mid 2} \sin \left(\theta_{1}-\theta_{3}\right)+\zeta_{\mathrm{PA} \mid 3} \sin \left(\theta_{2}-\theta_{1}\right)$.
} 


\section{Link's Planar Motion in the C-Space}

Figure 2 shows the pose and the characteristic vectors, ${ }^{\mathrm{s}} \mathbf{v}_{\mathrm{A} \mid \mathrm{r}}$ and $\omega_{\mathrm{rs}} \mathbf{k}$, of the velocity field of the relative planar motion of link $\mathrm{r}$ with respect to the frame, link s. In Fig. 2, i, j and $\mathbf{k}$ are the unit vectors of a righthanded Cartesian system fixed to the frame with the xy-coordinate plane coincident with the motion plane. $I_{r s}$ is the instant center. The positive direction of $\rho$ is given by a $90^{\circ}$ counterclockwise rotation of the unit vector $\tau\left(\equiv \mathbf{i} \cos \varphi_{\mathrm{A}}+\mathbf{j} \sin \varphi_{\mathrm{A}}\right)$, tangent to the path of point $\mathrm{A}$.

With reference to Fig. 2, the pose of link $\mathrm{r}$ can be individuated through the three-dimensional position vector (planar-pose vector referred to point A), ${ }^{\mathrm{s}} \mathbf{p}_{\mathrm{A} \mid \mathrm{r}}$, of link's c-space

${ }^{\mathrm{s}} \mathbf{p}_{\mathrm{A} \mid \mathrm{r}}=\mathrm{x}_{\mathrm{A}} \mathbf{i}+\mathrm{y}_{\mathrm{A}} \mathbf{j}+\theta_{\mathrm{rs}} \mathbf{k}$

where $x_{A}$ and $y_{A}$ are the coordinates of point $A$, which is fixed to link $r$, and $\left.\left.\theta_{r s} \in\right]-\pi, \pi\right]$ rad is the slope angle of a directed line fixed to link $r$. Also, the three-tuple $\left(\mathrm{x}_{\mathrm{A}}, \mathrm{y}_{\mathrm{A}}, \theta_{\mathrm{rs}}\right)$ collects the three generalized coordinates of link’s c-space.

The finite difference ${ }^{3} \Delta^{\mathrm{s}} \mathbf{p}_{\mathrm{A} \mid \mathrm{r}}=\left({ }^{\mathrm{s}} \mathbf{p}_{\mathrm{A} \mid \mathrm{r}}{ }^{(2)}-^{\mathrm{s}} \mathbf{p}_{\mathrm{A} \mid \mathrm{r}}{ }^{(1)}\right)$ of two planar-pose vectors, ${ }^{\mathrm{s}} \mathbf{p}_{\mathrm{A} \mid \mathrm{r}}{ }^{(2)}$ and ${ }^{\mathrm{s}} \mathbf{p}_{\mathrm{A} \mid \mathrm{r}}{ }^{(1)}$, referred to point $\mathrm{A}$ is a free vector of the c-space that represents an element of the special Euclidean group $\mathrm{SE}(2)$, that is, it corresponds to a finite planar displacement. The vector addition of two finite differences, $\Delta^{\mathrm{s}} \mathbf{p}_{\mathrm{A} \mid \mathrm{r}}{ }^{(1)}$ and $\Delta^{\mathrm{s}} \mathbf{p}_{\mathrm{A} \mid \mathrm{r}}{ }^{(2)}$, is the finite difference $\Delta^{\mathrm{s}} \mathbf{p}_{\mathrm{A} \mid \mathrm{r}}{ }^{(3)}$ that corresponds to the finite planar displacement performed by link $\mathrm{r}$ after it sequentially performs $\Delta^{\mathrm{s}} \mathbf{p}_{\mathrm{A} \mid \mathrm{r}}{ }^{(1)}$ and $\Delta^{\mathrm{s}} \mathbf{p}_{\mathrm{A} \mid \mathrm{r}}{ }^{(2)}$ or vice versa. Thus, link's c-space together with the above-defined planar-pose vectors is an affine space, that is, it has a structure that keeps many properties of the Euclidean space $\mathrm{E}^{3}$.

The time derivative of Eq. (5) yields

${ }^{\mathrm{s}} \xi_{\mathrm{A} \mid \mathrm{r}} \equiv{ }^{\mathrm{s}} \dot{\mathbf{p}}_{\mathrm{A} \mid \mathrm{r}}=\dot{\mathrm{x}}_{\mathrm{A}} \mathbf{i}+\dot{\mathrm{y}}_{\mathrm{A}} \mathbf{j}+\dot{\theta}_{\mathrm{rs}} \mathbf{k} \equiv{ }^{\mathrm{s}} \mathbf{v}_{\mathrm{A} \mid \mathrm{r}}+\omega_{\mathrm{rs}} \mathbf{k}=\omega_{\mathrm{rs}}\left[\mathbf{k} \times\left(\mathbf{A}-\mathbf{I}_{\mathrm{rs}}\right)+\mathbf{k}\right]=\omega_{\mathrm{rs}}\left[\rho_{\mathrm{rs}}\left(\mathbf{i} \cos \varphi_{\mathrm{A}}+\mathbf{j} \sin \varphi_{\mathrm{A}}\right)+\mathbf{k}\right]$

where the relationships $\omega_{\mathrm{rs}}=\dot{\theta}_{\mathrm{rs}}$ and ${ }^{\mathrm{s}} \mathbf{v}_{\mathrm{A} \mid \mathrm{r}}=\omega_{\mathrm{rs}} \mathbf{k} \times\left(\mathbf{A}-\mathbf{I}_{\mathrm{rs}}\right)$ have been used.

${ }^{\mathrm{s}} \xi_{\mathrm{A} \mid \mathrm{r}}\left(\equiv{ }^{\mathrm{s}} \mathbf{v}_{\mathrm{A} \mid \mathrm{r}}+\omega_{\mathrm{rs}} \mathbf{k}=\omega_{\mathrm{rs}}\left[\mathbf{k} \times\left(\mathbf{A}-\mathbf{I}_{\mathrm{rs}}\right)+\mathbf{k}\right]\right)$ is a three-dimensional vector (pose-rate vector referred to point A), tangent to the path of ${ }^{\mathrm{s}} \mathbf{p}_{\mathrm{A} \mid \mathrm{r}}$ in the c-space, which uniquely identifies the instantaneous motion of link r. The components both of ${ }^{\mathrm{s}} \mathbf{p}_{\mathrm{A} \mid \mathrm{r}}$ and of ${ }^{\mathrm{s}} \boldsymbol{\xi}_{\mathrm{A} \mid \mathrm{r}}$ are not homogeneous.

\footnotetext{
${ }^{3}$ The addition and subtraction of slope angles, $\theta_{\mathrm{r} s}$, must be computed by choosing the values congruent modulo $2 \pi$ that belong to the range $]-\pi, \pi]$ rad.
} 
The formulas [i.e., $\left.{ }^{\mathrm{s}} \mathbf{v}_{\mathrm{B} \mid \mathrm{r}}={ }^{\mathrm{s}} \mathbf{v}_{\mathrm{A} \mid \mathrm{r}}+\omega_{\mathrm{rs}} \mathbf{k} \times(\mathbf{B}-\mathbf{A})\right]$ of rigid-body's instantaneous kinematics [2, 10] bring to conclude that the pose-rate vector referred to point $\mathrm{A},{ }^{\mathrm{s}} \xi_{\mathrm{A} \mid \mathrm{r}}$, must be related to the pose-rate vector referred to point $\mathrm{B},{ }^{\mathrm{s}} \xi_{\mathrm{B} \mid \mathrm{r}}$, by the following relationship (pose-rate transport formula)

${ }^{s} \xi_{\mathrm{B} \mid \mathrm{r}}={ }^{\mathrm{s}} \mathbf{v}_{\mathrm{B} \mid \mathrm{r}}+\omega_{\mathrm{rs}} \mathbf{k}={ }^{\mathrm{s}} \boldsymbol{\xi}_{\mathrm{A} \mid \mathrm{r}}+\omega_{\mathrm{rs}}\left[\left(\mathrm{x}_{\mathrm{A}}-\mathrm{x}_{\mathrm{B}}\right) \mathbf{i}+\left(\mathrm{y}_{\mathrm{A}}-\mathrm{y}_{\mathrm{B}}\right) \mathbf{j}\right] \times \mathbf{k} \equiv{ }^{\mathrm{s}} \boldsymbol{\xi}_{\mathrm{A} \mid \mathrm{r}}+\omega_{\mathrm{rs}}\left[\left(\mathrm{y}_{\mathrm{A}}-\mathrm{y}_{\mathrm{B}}\right) \mathbf{i}-\left(\mathrm{x}_{\mathrm{A}}-\mathrm{x}_{\mathrm{B}}\right) \mathbf{j}\right]$

where the relationship $(\mathbf{A}-\mathbf{B})=\left(\mathrm{x}_{\mathrm{A}}-\mathrm{x}_{\mathrm{B}}\right) \mathbf{i}+\left(\mathrm{y}_{\mathrm{A}}-\mathrm{y}_{\mathrm{B}}\right) \mathbf{j}$ has been used.

The relative motion theorems, which yields the composition rules of rigid-body's velocity fields [10], bring to conclude that

- the vector sum of two pose-rate vectors, say ${ }^{s} \xi_{\mathrm{A} \mid \mathrm{r}}{ }^{(1)}$ and ${ }^{\mathrm{s}} \xi_{\mathrm{A} \mid \mathrm{r}}{ }^{(2)}$, both referred to the same point, $\mathrm{A}$, is the pose-rate vector, say ${ }^{\mathrm{s}} \xi_{\mathrm{A} \mid \mathrm{r}}{ }^{(3)}$, that identifies the planar velocity field obtained through the composition of the two planar velocity fields represented by ${ }^{\mathrm{s}} \xi_{\mathrm{A} \mid \mathrm{r}}^{(1)}$ and ${ }^{\mathrm{s}} \xi_{\mathrm{A} \mid \mathrm{r}}{ }^{(2)}$;

- the product of ${ }^{\mathrm{s}} \xi_{\mathrm{A} \mid \mathrm{r}}$ (Fig. 2) by a real number, say $\lambda$, is the pose-rate vector that represents the planar velocity field with the same instant center and angular velocity $\lambda \omega_{\mathrm{rs}} \mathbf{k}$.

Therefore, the set of pose-rate vectors referred to point $\mathrm{A},\left\{\xi_{\mathrm{A} \mid \mathrm{r}}(\mathrm{i})\right\}$, together with the two abovedefined operations of vector addition and scalar multiplication is a vector space over the real numbers. The pure translations, ${ }^{\mathrm{s}} \boldsymbol{v}_{\mathrm{r}}=\omega_{\mathrm{rs}} \mathbf{k} \times\left(\mathbf{I}_{\mathrm{rs}}{ }^{(2)}-\mathbf{I}_{\mathrm{rs}}{ }^{(1)}\right)$, are elements of $\left\{{ }^{\mathrm{s}} \boldsymbol{\xi}_{\mathrm{A} \mid \mathrm{r}}{ }^{(\mathrm{i})}\right\}$ that are obtained by summing two pose-rate vectors, ${ }^{\mathrm{s}} \xi_{\mathrm{A} \mid \mathrm{r}}{ }^{(1)}$ and ${ }^{\mathrm{s}} \xi_{\mathrm{A} \mid \mathrm{r}}{ }^{(2)}$, with equal and opposite angular velocities, that is, $\omega_{\mathrm{rs}}=\omega_{\mathrm{rs}}{ }^{(1)}=-\omega_{\mathrm{rs}}{ }^{(2)}$, and non-coincident instant centers, that is, $\mathbf{I}_{\mathrm{rs}}{ }^{(1)} \neq \mathbf{I}_{\mathrm{rs}}{ }^{(2)}$.

With reference to Fig. 2, the following unit pose-rate vector referred to point A can be defined

${ }^{\mathrm{s}} \boldsymbol{\pi}_{\mathrm{A} \mid \mathrm{r}}=\rho_{\mathrm{rs}}\left(\mathbf{i} \cos \varphi_{\mathrm{A}}+\mathbf{j} \sin \varphi_{\mathrm{A}}\right)+\mathbf{k}=\rho_{\mathrm{rs}} \boldsymbol{\tau}+\mathbf{k}$

which gives the position of the instant center $I_{r s}$ through the relationship (Fig. 2)

$\left(\mathbf{I}_{\mathrm{rs}}-\mathbf{A}\right)=\mathbf{k} \times{ }^{\mathrm{s}} \pi_{\mathrm{A} \mid \mathrm{r}} \equiv \rho_{\mathrm{rs}}\left(\mathbf{j} \cos \varphi_{\mathrm{A}}-\mathbf{i} \sin \varphi_{\mathrm{A}}\right)=\rho_{\mathrm{rs}} \mathbf{k} \times \tau$ 
It is worth stressing that the cross product $\sigma_{\mathrm{A} \mid 1 \times \sigma_{\mathrm{A} \mid 2}}$ of two unit planar wrenches ${ }^{4}$ yields a vector whose components have the same dimensional units of the homologous components of a unit pose-rate vector.

The pose-rate vector addition

$\mathrm{s} \xi_{\mathrm{A} \mid \mathrm{r}}=\sum_{\mathrm{j}=1, \mathrm{n}}^{\mathrm{s}} \boldsymbol{\xi}_{\mathrm{A} \mid \mathrm{r}}{ }^{(\mathrm{j})}$

where ${ }^{\mathrm{s}} \xi_{\mathrm{A} \mid \mathrm{r}}$ is given by Eq. (6) and

${ }^{s} \xi_{A \mid r}{ }^{(j)}={ }^{s} \mathbf{v}_{A \mid r}{ }^{(j)}+\omega_{r s}{ }^{(j)} \mathbf{k}=\omega_{r s}{ }^{(j)}\left[\mathbf{k} \times\left(\mathbf{A}-\mathbf{I}_{r s}{ }^{(j)}\right)+\mathbf{k}\right]=\omega_{r s}{ }^{(j)}\left[\rho_{r s}{ }^{(j)}\left(\mathbf{i} \cos \varphi_{A}{ }^{(j)}+\mathbf{j} \sin \varphi_{A}{ }^{(j)}\right)+\mathbf{k}\right], \quad j=1, \ldots, n,(10 b)$

brings to conclude that the following relationships hold

$$
\begin{aligned}
& \omega_{\mathrm{rs}} \rho_{\mathrm{rs}} \cos \varphi_{\mathrm{A}}=\sum_{\mathrm{j}=1, \mathrm{n}} \omega_{\mathrm{rs}}{ }^{(\mathrm{j})} \rho_{\mathrm{rs}}{ }^{(\mathrm{j})} \cos \varphi_{\mathrm{A}}{ }^{(\mathrm{j})} \\
& \omega_{\mathrm{rs}} \rho_{\mathrm{rs}} \sin \varphi_{\mathrm{A}}=\sum_{\mathrm{j}=1, \mathrm{n}} \omega_{\mathrm{rs}}{ }^{(\mathrm{j})} \rho_{\mathrm{rs}}{ }^{(\mathrm{j})} \sin \varphi_{\mathrm{A}}{ }^{(\mathrm{j})} \\
& \omega_{\mathrm{rs}}=\sum_{\mathrm{j}=1, \mathrm{n}} \omega_{\mathrm{rs}}{ }^{(\mathrm{j})}
\end{aligned}
$$

Equations (11) are summed up by the following vector relationship

$\omega_{\mathrm{rs}}\left(\mathbf{I}_{\mathrm{rs}}-\mathbf{A}\right)=\sum_{\mathrm{j}=1, \mathrm{n}} \omega_{\mathrm{rs}}^{(\mathrm{j})}\left(\mathbf{I}_{\mathrm{rs}}{ }^{(\mathrm{j})}-\mathbf{A}\right)$

which can be generalized to the composition of $\mathrm{n}$ instantaneous rotations plus $\mathrm{m}$ instantaneous translations, ${ }^{\mathrm{s}} \mathbf{V}_{\mathrm{r}}{ }^{(\mathrm{p})}\left[\equiv \omega_{\mathrm{rs}}{ }^{(\mathrm{p})} \mathbf{k} \times\left(\mathbf{I}_{\mathrm{rs}}{ }^{(\mathrm{p}, 2)}-\mathbf{I}_{\mathrm{rs}}{ }^{(\mathrm{p}, 1)}\right)\right]$ for $\mathrm{p}=1, \ldots, \mathrm{m}$, as follows

$$
\begin{aligned}
& \omega_{\mathrm{rs}}\left(\mathbf{I}_{\mathrm{rs}}-\mathbf{A}\right)=\sum_{\mathrm{j}=1, \mathrm{n}} \omega_{\mathrm{rs}}{ }^{(\mathrm{j})}\left(\mathbf{I}_{\mathrm{rs}}{ }^{(\mathrm{j})}-\mathbf{A}\right)+\mathbf{k} \times\left(\sum_{\mathrm{p}=1, \mathrm{~m}}{ }^{\mathrm{s}} \mathbf{v}_{\mathrm{r}}{ }^{(\mathrm{p})}\right) \\
& \omega_{\mathrm{rs}}=\sum_{\mathrm{j}=1, \mathrm{n}} \omega_{\mathrm{rs}}{ }^{(\mathrm{j})}
\end{aligned}
$$

${ }^{4}$ If $\boldsymbol{\sigma}_{\mathrm{A} \mid}=\cos \theta_{1} \mathbf{i}+\sin \theta_{1} \mathbf{j}+\zeta_{\mathrm{PA} \mid} \mathbf{k}$ and $\boldsymbol{\sigma}_{\mathrm{A} \mid 2}=\cos \theta_{2} \mathbf{i}+\sin \theta_{2} \mathbf{j}+\zeta_{\mathrm{PA} \mid 2} \mathbf{k}$, then $\sigma_{\mathrm{A} \mid 1} \times \boldsymbol{\sigma}_{\mathrm{A} \mid 2}=\zeta_{\mathrm{PA} \mid 1}\left(\cos \theta_{2} \mathbf{j}-\sin \theta_{2} \mathbf{i}\right)-\zeta_{\mathrm{PA} \mid 2}\left(\cos \theta_{1} \mathbf{j}-\sin \theta_{1} \mathbf{i}\right)+\sin \left(\theta_{2}-\theta_{1}\right) \mathbf{k}$. 
Equations (12) and (13) shows that

STATEMENT I: the instant center of a planar instantaneous motion obtained through the composition of a number of rigid-body's instantaneous motions coincides with the centroid of the instant centers of the component motions with weights given by the signed magnitudes of their angular velocities.

This statement, which, here, comes out in a simple and direct way, was first highlighted in [11] where it was deduced with a more cumbersome procedure and used to study the singularities of planar mechanisms.

\subsection{Virtual work and duality between planar wrenches and pose rates}

The power, $\mathrm{w}_{\mathrm{rs}}$, that a planar force system, represented by the planar wrench $\mathbf{\$}_{\mathrm{A}}$, introduces into the mechanical system "link r", when it performs the instantaneous motion represented by the pose-rate vector ${ }^{\mathrm{s}} \xi_{\mathrm{A} \mid \mathrm{r}}$, can be written as follows (see Figs. 1 and 2)

$\mathrm{W}_{\mathrm{rs}}=\$_{\mathrm{A}} \cdot{ }^{s} \xi_{\mathrm{A} \mid \mathrm{r}}=\mathrm{f} \omega_{\mathrm{rs}} \sigma_{\mathrm{A}} \cdot{ }^{\mathrm{s}} \pi_{\mathrm{Al}}=\mathrm{f} \omega_{\mathrm{rs}}\left[\rho_{\mathrm{rs}}\left(\cos \theta \cos \varphi_{\mathrm{A}}+\sin \theta \sin \varphi_{\mathrm{A}}\right)+\zeta_{\mathrm{PA}}\right] \equiv \mathrm{f} \omega_{\mathrm{rS}}\left[\rho_{\mathrm{rs}} \cos \left(\theta-\varphi_{\mathrm{A}}\right)+\zeta_{\mathrm{PA}}\right]$

Even though the dot product in $\left\{\mathbf{S}_{\mathrm{A}}^{(\mathrm{i})}\right\}$ and in $\left\{\xi_{\mathrm{A} \mid \mathrm{r}}^{(\mathrm{i})}\right\}$ cannot be defined since the components both of $\boldsymbol{\$}_{\mathrm{A}}$ and of ${ }^{\mathrm{s}} \xi_{\mathrm{A} \mid \mathrm{r}}$ are not homogeneous, the dot product between one element of $\left\{\boldsymbol{\$}_{\mathrm{A}}{ }^{(\mathrm{i})}\right\}$ and one element of $\left\{\xi_{A \mid r}^{(i)}\right\}$, which appears in Eq. (14), is well defined provided that the product of the measurement units of the homologous components of $\$_{\mathrm{A}}$ and of ${ }^{\mathrm{s}} \xi_{\mathrm{Al} \mid \mathrm{r}}$ yields the same measurement unit of the power.

From the algebraic point of view, the dot product of Eq. (14) can be interpreted both as the general expression of a linear map $\left\{\boldsymbol{\$}_{\mathrm{A}}^{(\mathrm{i})}\right\} \rightarrow \mathrm{R}$ and as the general expression of a linear map $\left\{\boldsymbol{\xi}_{\mathrm{A} \mid \mathrm{r}}^{(\mathrm{i})}\right\} \rightarrow \mathrm{R}$. Therefore, Eq. (14) shows that $\left\{{ }^{\mathrm{s}} \xi_{\mathrm{A} \mid \mathrm{r}}^{(\mathrm{i})}\right\}$ is the dual space of $\left\{\mathbf{S}_{\mathrm{A}}^{(\mathrm{i})}\right\}$ and vice versa (i.e., $\left\{\mathbf{S}_{\mathrm{A}}^{(\mathrm{i})}\right\}$ is the dual space of $\left.\left\{{ }^{\mathrm{s}} \xi_{\mathrm{Al}}{ }^{(\mathrm{i})}\right\}\right)$.

The virtual work, $\delta \mathrm{L}_{\mathrm{rs}}$, of $\boldsymbol{\$}_{\mathrm{A}}$ due to the virtual displacement $\delta^{\mathrm{s}} \mathbf{p}_{\mathrm{A} \mid \mathrm{r}}\left(\equiv \delta \mathrm{x}_{\mathrm{A}} \mathbf{i}+\delta \mathrm{y}_{\mathrm{A}} \mathbf{j}+\delta \theta_{\mathrm{rs}} \mathbf{k}=\delta \theta_{\mathrm{rs}}\left[\rho_{\mathrm{rs}}(\mathbf{i}\right.\right.$ $\left.\left.\left.\cos \varphi_{\mathrm{A}}+\mathbf{j} \sin \varphi_{\mathrm{A}}\right)+\mathbf{k}\right]\right)$ of link $\mathrm{r}$ is

$\delta \mathrm{L}_{\mathrm{rs}}=\boldsymbol{\$}_{\mathrm{A}} \cdot \delta^{\mathrm{s}} \mathbf{p}_{\mathrm{A} \mid \mathrm{r}}=\left(\mathrm{f} \boldsymbol{\sigma}_{\mathrm{A}} \cdot{ }^{\mathrm{s}} \pi_{\mathrm{A} \mid \mathrm{r}}\right) \delta \theta_{\mathrm{rs}}=\mathrm{f} \delta \theta_{\mathrm{rs}}\left[\rho_{\mathrm{rs}}\left(\cos \theta \cos \varphi_{\mathrm{A}}+\sin \theta \sin \varphi_{\mathrm{A}}\right)+\zeta_{\mathrm{PA}}\right] \equiv \mathrm{f} \delta \theta_{\mathrm{rs}}\left[\rho_{\mathrm{rs}} \cos \left(\theta-\varphi_{\mathrm{A}}\right)+\zeta_{\mathrm{PA}}\right]$ 
Moreover, if $\delta^{\mathrm{s}} \mathbf{p}_{\mathrm{A} \mid \mathrm{r}}$ is obtained by combining a number of independent instantaneous virtual motions as it happens when link $r$ belongs to a multi-degrees-of-freedom (multi-dof) planar mechanism [11], it can be expressed as follows

$\delta^{\mathrm{s}} \mathbf{p}_{\mathrm{A} \mid \mathrm{r}}=\sum_{\mathrm{j}=1, \mathrm{n}}{ }^{\mathrm{s}} \boldsymbol{\pi}_{\mathrm{A} \mid \mathrm{r}}{ }^{(\mathrm{j})} \delta \theta_{\mathrm{rs}}{ }^{(\mathrm{j})}=\sum_{\mathrm{j}=1, \mathrm{n}}\left[\mathbf{k} \times\left(\mathbf{A}-\mathbf{I}_{\mathrm{rs}}{ }^{(\mathrm{j})}\right)+\mathbf{k}\right] \delta \theta_{\mathrm{rs}}{ }^{(\mathrm{j})}$

and Eq. (15) becomes

$\delta \mathrm{L}_{\mathrm{rs}}=\boldsymbol{\$}_{\mathrm{A}} \cdot \delta^{\mathrm{s}} \mathbf{p}_{\mathrm{A} \mid \mathrm{r}}=\mathrm{f} \sum_{\mathrm{j}=1, \mathrm{n}}\left(\boldsymbol{\sigma}_{\mathrm{A}} \cdot{ }^{\mathrm{s}} \boldsymbol{\pi}_{\mathrm{A} \mid \mathrm{r}}{ }^{(\mathrm{j})}\right) \delta \theta_{\mathrm{rs}}{ }^{(\mathrm{j})} \equiv \mathrm{f} \sum_{\mathrm{j}=1, \mathrm{n}}\left[\rho_{\mathrm{rs}}{ }^{(\mathrm{j})} \cos \left(\theta-\varphi_{\mathrm{A}}{ }^{(\mathrm{j})}\right)+\zeta_{\mathrm{PA}}\right] \delta \theta_{\mathrm{rs}}{ }^{(\mathrm{j})}$

where the $\mathrm{j}$-th $\delta \theta_{\mathrm{rs}}{ }^{(\mathrm{j})}$ and $\mathrm{I}_{\mathrm{rs}}{ }^{(\mathrm{j})}$ are the virtual rotation and the instant center of the virtual motion link $\mathrm{r}$ performs when all the inputs of the n-dof mechanism are locked, but the j-th one [11]. $\delta \theta_{\mathrm{rs}}{ }^{(\mathrm{j})}$ is related to the virtual change, $\delta q_{j}$, of the $\mathrm{j}$-th input, $\mathrm{q}_{\mathrm{j}}$, by a linear and homogeneous relationship [11].

If the planar force system represented by $\$_{\mathrm{A}}$ is applied to link $\mathrm{r}$ through an $\mathrm{n}$-dof passive kinematic chain $^{5}$ which joins it to the frame, link $\mathrm{s}$, the virtual work $\delta \mathrm{L}_{\mathrm{rs}}$ must be equal to zero. According to Eq. (17), this can happen iff $\sigma_{\mathrm{A}}$, which identifies the central axis of the force system, is perpendicular to all the ${ }^{\mathrm{s}} \pi_{\mathrm{A} \mid \mathrm{r}}{ }^{(\mathrm{j})}$, for $\mathrm{j}=1, \ldots, \mathrm{n}$, which identify the instant centers $\mathrm{I}_{\mathrm{rs}}{ }^{(\mathrm{j})}$. Since the zeroing of $\delta \mathrm{L}_{\mathrm{rs}}$ does not depend on the choice of the reduction point A, without loosing generality, a point of the force-system central axis can be chosen as point A. This choice makes $\zeta_{\mathrm{PA}}$ equal to zero in Eq. (17) and makes Eq. (17) highlight that, with this choice, all the $\rho_{\mathrm{rs}}{ }^{(\mathrm{j})}$ must be equal to zero to give $\delta \mathrm{L}_{\mathrm{rs}}=0$, that is, the following statement holds

STATEMENT II: a planar passive n-dof kinematic chain can transmit only a force system whose central axis passes through all the instant centers $I_{r s}^{(j)}$ for $j=1, \ldots, n$.

The following corollaries come from statement II

(II.a) a single-dof planar passive kinematic chain can transmit only force systems whose central axis belongs to the pencil of lines passing through the unique $\mathrm{I}_{\mathrm{rs}}$ (Fig. 3(a));

(II.b) a two-dof planar passive kinematic chain can transmit only one force with line of action that passes through $\mathrm{I}_{\mathrm{rs}}{ }^{(1)}$ and $\mathrm{I}_{\mathrm{rs}}{ }^{(2)}$ (Figs. 3(b) and 3(c));

(II.c) an n-dof planar passive kinematic chain with $\mathrm{n} \geq 3$ cannot transmit any force system.

${ }^{5}$ Here, "passive" means without actuators. Moreover, all the kinematic pairs are supposed "ideal constraints" (i.e., without friction). 
Figure 3 shows the force systems that can be transmitted through a passive four-bar linkage (Fig. 3(a)), a passive RR (Fig. 3(b)) and a passive RP (Fig. 3(c)) kinematic chain ${ }^{6}$.

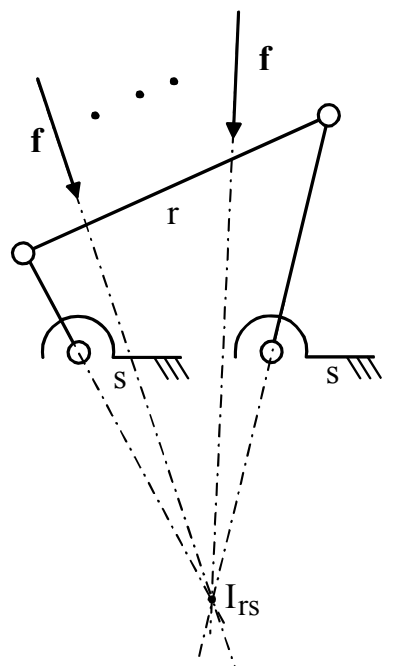

(a)

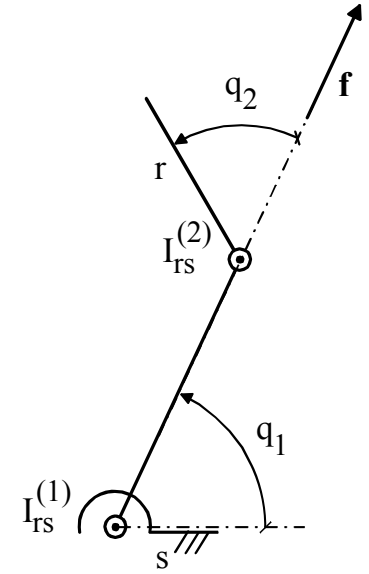

(b)

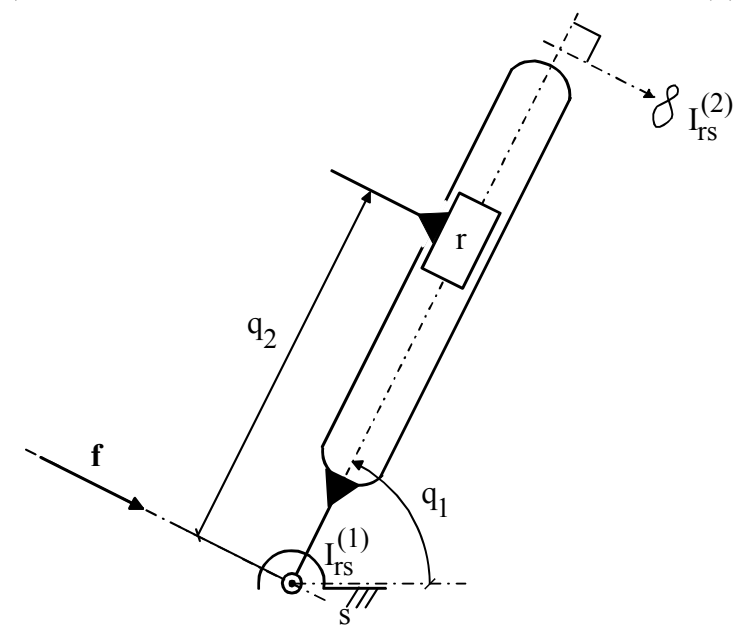

(c)

Figure 3: Force systems transmitted through a passive four-bar linkage (a), a passive RR (b) and a passive RP (c) kinematic chain.

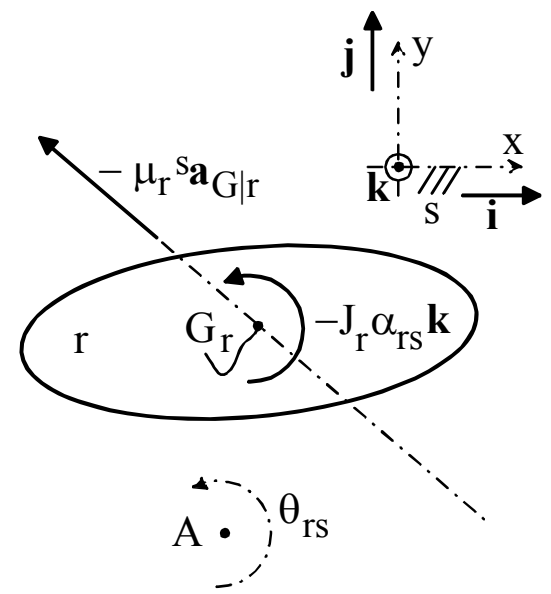

Figure 4: Inertia forces of link $r$ reduced to its center of mass: $G r$, $\mu_{r}$ and $J_{r}$ are the center of mass, the mass and the mass moment of inertia about the axis perpendicular to the motion plane and passing through $G$, respectively, of link $r$.

${ }^{6} \mathrm{R}$ and $\mathrm{P}$ denote revolute and prismatic pair, respectively. 


\section{Newton's Laws of the C-Space}

Point kinematics of link's c-space is completed by further time differentiating Eq. (6) to obtain the threedimensional vector (pose-acceleration vector referred to point A)

${ }^{\mathrm{s}} \boldsymbol{f}_{\mathrm{A} \mid \mathrm{r}}={ }^{\mathrm{s}} \dot{\boldsymbol{\xi}}_{\mathrm{A} \mid \mathrm{r}} \equiv{ }^{\mathrm{s}} \ddot{\mathbf{p}}_{\mathrm{A} \mid \mathrm{r}}=\ddot{\mathrm{x}}_{\mathrm{A}} \mathbf{i}+\ddot{\mathrm{y}}_{\mathrm{A}} \mathbf{j}+\ddot{\theta}_{\mathrm{rs}} \mathbf{k} \equiv{ }^{\mathrm{s}} \mathbf{a}_{\mathrm{A} \mid \mathrm{r}}+\alpha_{\mathrm{rs}} \mathbf{k}=\alpha_{\mathrm{rs}}\left[\mathbf{k} \times\left(\mathbf{A}-\mathbf{D}_{\mathrm{rs}}\right)+\mathbf{k}\right]-\omega_{\mathrm{rs}}{ }^{2}\left(\mathbf{A}-\mathbf{D}_{\mathrm{rs}}\right)$

where $\alpha_{\mathrm{rs}} \equiv \dot{\omega}_{\mathrm{rs}}=\ddot{\theta}_{\mathrm{rs}}$ and $\mathrm{D}_{\mathrm{rs}}$ is the instantaneous center of acceleration; whereas, ${ }^{\mathrm{s}} \mathbf{a}_{\mathrm{A} \mid \mathrm{r}}$ and $\alpha_{\mathrm{rs}} \mathbf{k}$, are the acceleration of point $\mathrm{A}$ and the angular acceleration of link $\mathrm{r}$ in the planar motion of link $\mathrm{r}$ with respect to the frame, link s.

The vector ' ${ }^{\boldsymbol{f}_{\mathrm{A} \mid \mathrm{r}}}$ gives the acceleration of the point of link's c-space and sums up the acceleration characteristics of the acceleration field of link r. Unfortunately, it has no further properties.

The characterization of the inertia forces of link $r$ through a planar wrench is more interesting than the characterization of its acceleration field. Figure 4 shows the inertia forces of link r reduced to its center of mass: $G_{r}, \mu_{r}$ and $J_{r}$ are the center of mass, the mass and the mass moment of inertia about the axis perpendicular to the motion plane and passing through $G_{r}$, respectively, of link $r$. This force system can be represented through the planar wrench (inertia planar wrench) about $G_{r}$

$\$_{\mathrm{G} \mid \mathrm{r}, \mathrm{in}}=-\mu_{\mathrm{r}}{ }^{\mathrm{s}} \mathbf{a}_{\mathrm{G} \mid \mathrm{r}}-\mathrm{J}_{\mathrm{r}} \alpha_{\mathrm{rs}} \mathbf{k}=-\mu_{\mathrm{r}}\left[{ }^{\mathrm{s}} \mathbf{a}_{\mathrm{G} \mid \mathrm{r}}+\delta_{\mathrm{r}}^{2} \alpha_{\mathrm{rs}} \mathbf{k}\right]$

where ${ }^{\mathrm{s}} \mathbf{a}_{\mathrm{G} \mid \mathrm{r}}$ is the acceleration of $\mathrm{G}_{\mathrm{r}}$ and the relationship $\mathrm{J}_{\mathrm{r}}=\mu_{\mathrm{r}} \delta_{\mathrm{r}}^{2}$, where $\delta_{\mathrm{r}}$ is the radius of gyration of link r, has been used.

By using planar wrenches' transport formula (Eq. (3)), $\mathbf{S}_{\mathrm{G} \mid \mathrm{r} \text {,in }}$ can be reduced to point A as follows

$$
\begin{aligned}
\boldsymbol{\$}_{\mathrm{A} \mid \mathrm{r}, \text { in }} & =\boldsymbol{\$}_{\mathrm{G} \mid \mathrm{r}, \mathrm{in}}-\mu_{\mathrm{r}}\left(\mathbf{G}_{\mathrm{r}}-\mathbf{A}\right) \times{ }^{\mathrm{s}} \mathbf{a}_{\mathrm{G} \mid \mathrm{r}} \equiv \boldsymbol{\$}_{\mathrm{G} \mid \mathrm{r}, \mathrm{in}}-\mu_{\mathrm{r}}\left[\left(\mathrm{x}_{\mathrm{G} \mid \mathrm{r}}-\mathrm{x}_{\mathrm{A}}\right) \ddot{\mathrm{y}}_{\mathrm{G} \mid \mathrm{r}}-\left(\mathrm{y}_{\mathrm{G} \mid \mathrm{r}}-\mathrm{y}_{\mathrm{A}}\right) \ddot{\mathrm{x}}_{\mathrm{G} \mid \mathrm{r}}\right] \mathbf{k} \equiv \\
& \equiv-\mu_{\mathrm{r}}\left\{{ }^{\mathrm{s}} \mathbf{a}_{\mathrm{G} \mid \mathrm{r}}+\left[\delta_{\mathrm{r}}{ }^{2} \alpha_{\mathrm{rs}}+\left(\mathrm{x}_{\mathrm{G} \mid \mathrm{r}}-\mathrm{x}_{\mathrm{A}}\right) \ddot{\mathrm{y}}_{\mathrm{G} \mid \mathrm{r}}-\left(\mathrm{y}_{\mathrm{G} \mid \mathrm{r}}-\mathrm{y}_{\mathrm{A}}\right) \ddot{\mathrm{x}}_{\mathrm{G} \mid \mathrm{r}}\right] \mathbf{k}\right\} \equiv-\mu_{\mathrm{r}}\left\{{ }^{\mathrm{s}} \mathbf{a}_{\mathrm{G} \mid \mathrm{r}}+\left[\mathbf{k} \cdot\left(\mathbf{G}_{\mathrm{r}}-\mathbf{A}\right) \times{ }^{\mathrm{s}} \mathbf{a}_{\mathrm{G} \mid \mathrm{r}}+\delta_{\mathrm{r}}{ }^{2} \alpha_{\mathrm{rs}}\right] \mathbf{k}\right\}
\end{aligned}
$$

where the relationship $\left(\mathbf{G}_{\mathrm{r}}-\mathbf{A}\right)=\left(\mathrm{x}_{\mathrm{G} \mid \mathrm{r}}-\mathrm{x}_{\mathrm{A}}\right) \mathbf{i}+\left(\mathrm{y}_{\mathrm{G} \mid \mathrm{r}}-\mathrm{y}_{\mathrm{A}}\right) \mathbf{j}$ has been used. 
By using the introduced vectors, the motion equation of the c-space point ${ }^{\mathrm{s}} \mathbf{p}_{\mathrm{G} \mid \mathrm{r}}\left[{ } \mathrm{x}_{\mathrm{G} \mid \mathbf{i}} \mathbf{i}+\mathrm{y}_{\mathrm{G} \mid \mathbf{j}} \mathbf{j}+\theta_{\mathrm{rs}} \mathbf{k}\right]$ can be written as follows

$\mathbf{\$}_{\mathrm{A} \mid \mathrm{r}, \mathrm{ex}}+\boldsymbol{\$}_{\mathrm{A} \mid \mathrm{r}, \mathrm{co}}+\boldsymbol{\$}_{\mathrm{A} \mid \mathrm{r}, \text { in }}=\mathbf{0}$

or in the form (which is similar to the II Newton's law of classical mechanics [12])

$\mathbf{\$}_{\mathrm{A} \mid \mathrm{r}, \mathrm{ex}}+\mathbf{S}_{\mathrm{A} \mid \mathrm{r}, \mathrm{co}}=\mu_{\mathrm{r}}\left\{\mathbf{a}_{\mathrm{G} \mid \mathrm{r}}+\left[\mathbf{k} \cdot\left(\mathbf{G}_{\mathrm{r}}-\mathbf{A}\right) \times \times^{\mathrm{s}} \mathbf{a}_{\mathrm{G} \mid \mathrm{r}}+\delta_{\mathrm{r}}^{2} \alpha_{\mathrm{rs}}\right] \mathbf{k}\right\}$

where $\$_{\mathrm{A} \mid \mathrm{r}, \mathrm{ex}}$ and $\boldsymbol{\$}_{\mathrm{A} \mid \mathrm{r}, \mathrm{co}}$ are the planar wrenches about point $\mathrm{A}$ of the external force systems and of the constraint forces, respectively, applied to link r.

Equation (21b) suggests defining the following three-dimensional vector (effective-acceleration vector of link r referred to point A)

${ }^{\mathrm{s}} \boldsymbol{\chi}_{\mathrm{A} \mid \mathrm{r}, \mathrm{ef}}={ }^{\mathrm{s}} \mathbf{a}_{\mathrm{G} \mid \mathrm{r}}+\left[\mathbf{k} \cdot\left(\mathbf{G}_{\mathrm{r}}-\mathbf{A}\right) \times{ }^{\mathrm{s}} \mathbf{a}_{\mathrm{G} \mid \mathrm{r}}+\delta_{\mathrm{r}}^{2} \alpha_{\mathrm{rs}}\right] \mathbf{k}$

which must be related to the effective-acceleration vector of link $r$ referred to point $\mathrm{B},{ }^{\mathrm{s}} \chi_{\mathrm{B} \mid \mathrm{r}, \mathrm{ef}}$, through the following transport formula

${ }^{\mathrm{s}} \boldsymbol{\chi}_{\mathrm{B} \mid \mathrm{r}, \mathrm{ef}}={ }^{\mathrm{s}} \boldsymbol{\chi}_{\mathrm{A} \mid \mathrm{r}, \mathrm{ef}}+\left[\mathbf{k} \cdot(\mathbf{A}-\mathbf{B}) \times{ }^{\mathrm{s}} \mathbf{a}_{\mathrm{G} \mid \mathrm{r}}\right] \mathbf{k}$

The use of the effective acceleration of link $r$ makes it possible to enunciate the motion law (Eq. (21b)) of the mechanics of a point of link's c-space in a way very similar to the II Newton's law as follows:

MOTION LAW (II LAW): the resultant of the planar wrenches about A applied to a link is equal to product of the effective acceleration of the same link referred to point A by the mass of the link.

A corollary of this motion law is the following "inertia law"

INERTIA LAW (I LAW): an isolated link keeps constant its pose-rate vector.

Eventually, since the interaction forces between links are the constraint forces, the following principle of action and reaction can be stated in the c-space 
ACTION-REACTION LAW (III LAW): if link $j$ applies a planar wrench $\$_{A l i, j}$ to link $i$, link $i$ will apply to link $j$ an equal and opposite planar wrench $\$_{A \mid j, i}=-\$_{A \mid i, j}$.

These "Newton's laws" of link's c-space allow planar mechanisms' dynamics to be modelled as a number of c-space's points that mutually interact by applying planar wrenches and simultaneously equilibrate external planar wrenches applied to them. In particular, Eq. (21b) must be written for each mobile link of the mechanism by using the same reference point for all the links. Also, the motion of the links can be visualized in the c-space as paths of points located by the above-defined planar-pose vectors. It is worth stressing that, since the xy-coordinate plane of the c-space is the motion plane, this representation of the mechanism motion can keep in the xy-plane all the ordinary representations of the mechanism motion that are usually drawn in the motion plane.

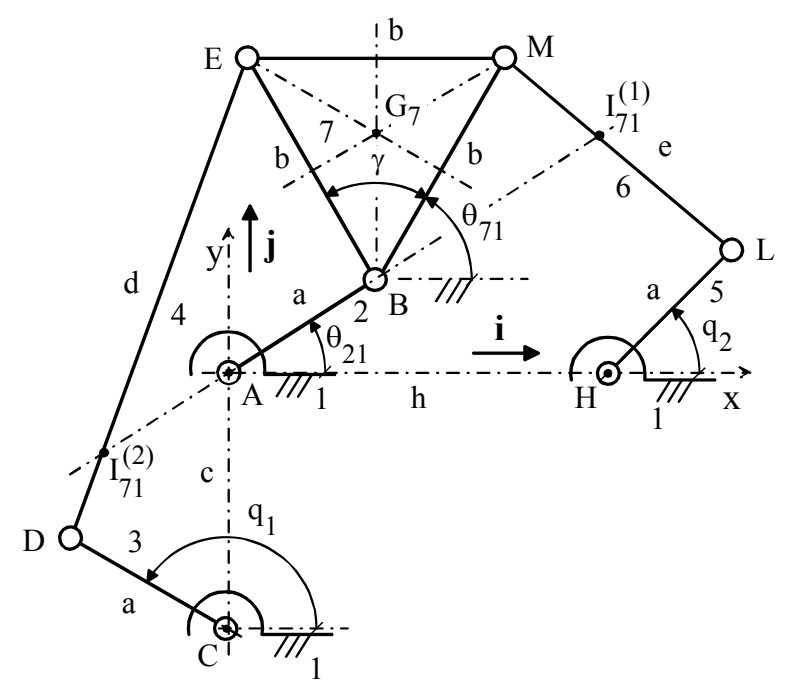

Figure 5: The 2ㅅRR-RR parallel planar mechanism: notations $\left(\gamma=60^{\circ}\right)$.

\section{Case Study}

Figure 5 shows a $2 \underline{R} R R-R^{7}$ parallel planar mechanism ${ }^{8}(\mathrm{PPM})$. This two-dof mechanism features an output ternary link, link $7(\mathrm{r}=7)$, joined to the frame, link $1(\mathrm{~s}=1)$, through two $\underline{R} R R$ dyads and one RR passive kinematic chain. With reference to Fig. $5, \mathrm{q}_{1}$ and $\mathrm{q}_{2}$ are the actuated-joint variables; $a$ is the length of the three cranks, that is, links 2,3 and 5 . The output link, link 7, is an equilateral triangle with side length equal to $\mathrm{b}$, center of mass $\mathrm{G}_{7}\left(\mathrm{BG}_{7}=\mathrm{b} / \sqrt{3}\right), \delta_{7}=\mathrm{b} /(2 \sqrt{3})$ and planar-pose vector, ${ }^{1} \mathbf{p}_{\mathrm{B} \mid 7}$, referred to point B which can be expressed as follows

\footnotetext{
${ }^{7}$ Hereafter, an underlined $\mathrm{R}$ denotes an actuated $\mathrm{R}$ pair.

${ }^{8}$ A PPM with 2 2 RR-RR architecture has been proposed by Pennock and Israr [13] as an adjustable six-bar linkage.
} 
${ }^{1} \mathbf{p}_{\mathrm{B} \mid 7}=\mathrm{a} \cos \theta_{21} \mathbf{i}+\mathrm{a} \sin \theta_{21} \mathbf{j}+\theta_{71} \mathbf{k}$

Also, $\mathrm{d}$ and e are the lengths of the binary links 4 and 6, respectively, and the following relationships hold

$(\mathbf{B}-\mathbf{A})=\mathrm{a} \cos \theta_{21} \mathbf{i}+\mathrm{a} \sin \theta_{21} \mathbf{j}$

$(\mathbf{D}-\mathbf{A})=\mathrm{a} \cos q_{1} \mathbf{i}+\left(\mathrm{a} \sin q_{1}-\mathrm{c}\right) \mathbf{j}$

$(\mathbf{L}-\mathbf{A})=\left(\mathrm{h}+\mathrm{a} \cos q_{2}\right) \mathbf{i}+\mathrm{a} \sin q_{2} \mathbf{j}$

$(\mathbf{M}-\mathbf{A})=\left(\mathrm{a} \cos \theta_{21}+\mathrm{b} \cos \theta_{71}\right) \mathbf{i}+\left(\mathrm{a} \sin \theta_{21}+\mathrm{b} \sin \theta_{71}\right) \mathbf{j}$

$(\mathbf{E}-\mathbf{A})=\left[\mathrm{a} \cos \theta_{21}+\mathrm{b} \cos \left(\theta_{71}+\gamma\right)\right] \mathbf{i}+\left[\mathrm{a} \sin \theta_{21}+\mathrm{b} \sin \left(\theta_{71}+\gamma\right)\right] \mathbf{j}$

$\left(\mathbf{G}_{7}-\mathbf{A}\right)=\left[\mathrm{a} \cos \theta_{21}+(\mathrm{b} / \sqrt{3}) \cos \left(\theta_{71}+\gamma / 2\right)\right] \mathbf{i}+\left[\mathrm{a} \sin \theta_{21}+(\mathrm{b} / \sqrt{3}) \sin \left(\theta_{71}+\gamma / 2\right)\right] \mathbf{j}$

which yield

$(\mathbf{M}-\mathbf{L})=\left[\mathrm{a} \cos \theta_{21}+\mathrm{b} \cos \theta_{71}-\left(\mathrm{h}+\mathrm{a} \cos q_{2}\right)\right] \mathbf{i}+\left[\mathrm{a} \sin \theta_{21}+\mathrm{b} \sin \theta_{71}-\mathrm{a} \sin q_{2}\right] \mathbf{j}$

$(\mathbf{E}-\mathbf{D})=\left[\mathrm{a} \cos \theta_{21}+\mathrm{b} \cos \left(\theta_{71}+\gamma\right)-\mathrm{a} \cos q_{1}\right] \mathbf{i}+\left[\mathrm{a} \sin \theta_{21}+\mathrm{b} \sin \left(\theta_{71}+\gamma\right)-\left(\mathrm{a} \sin q_{1}-\mathrm{c}\right)\right] \mathbf{j}$

and the following two scalar closure equations

$\mathrm{d}^{2}=(\mathbf{E}-\mathbf{D})^{2}=\left[\mathrm{a} \cos \theta_{21}+\mathrm{b} \cos \left(\theta_{71}+\gamma\right)-\mathrm{a} \cos q_{1}\right]^{2}+\left[\mathrm{a} \sin \theta_{21}+\mathrm{b} \sin \left(\theta_{71}+\gamma\right)-\left(\mathrm{a} \sin q_{1}-\mathrm{c}\right)\right]^{2}$

$\mathrm{e}^{2}=(\mathbf{M}-\mathbf{L})^{2}=\left[\mathrm{a} \cos \theta_{21}+\mathrm{b} \cos \theta_{71}-\left(\mathrm{h}+\mathrm{a} \cos q_{2}\right)\right]^{2}+\left[\mathrm{a} \sin \theta_{21}+\mathrm{b} \sin \theta_{71}-\mathrm{a} \sin q_{2}\right]^{2}$

Equations (27a) and (27b) allow the determination of the values of the two-tuple $\left(\theta_{21}, \theta_{71}\right)$, that is, of the poses of link 7, compatible with assigned values of $\mathrm{q}_{1}$ and $\mathrm{q}_{2}$ (direct position analysis (DPA)) and vice versa, that is, the determination of the values of $\mathrm{q}_{1}$ and $\mathrm{q}_{2}$ compatible with an assigned pose of link 7 (inverse position analysis (IPA)). The DPA of the studied mechanism coincides with the DPA of the 3RRR planar parallel manipulator [14-16] and it admits up to six solutions [14] that have been determined in analytical form in [15]. Also, the IPA simply consists in the determination of the up-to-two assembly modes of the two RRR dyads for an assigned position of their ending points (i.e., of points C and $\mathrm{E}$ for one dyad and of points $\mathrm{H}$ and $\mathrm{M}$ for the other (Fig. 5)); thus, it admits up to four solutions. 
The theoretical results deduced in Sec. 3 require the determination of the instant centers $I_{71}{ }^{(j)}, j=1,2$, to explain the kinetostatics of the $2 \underline{R} R R-R R$ mechanism. $\mathrm{I}_{71}{ }^{(1)}\left(\mathrm{I}_{71}{ }^{(2)}\right)$ is the position of $\mathrm{I}_{71}$ when $\mathrm{q}_{2}\left(\mathrm{q}_{1}\right)$ is locked. If either $\mathrm{q}_{1}$ or $\mathrm{q}_{2}$ are locked, the $2 \underline{R} R R-R R$ mechanism becomes a single-dof six-bar linkage [17] of Stephenson-III type [18-20] whose four-bar loop makes the determination of the related $I_{71}{ }^{(j)}, j=1,2$, possible [21].

In particular (see Figs. 3(a) and 5), when $\mathrm{q}_{2}$ is locked, L becomes a point of the frame and the points A, $\mathrm{B}, \mathrm{M}$ and $\mathrm{L}$ become the vertices of the four-bar loop that locates $\mathrm{I}_{71}{ }^{(1)}$ as common intersection between the line through $\mathrm{A}$ and $\mathrm{B}$, which is fixed to link 2, and the line through $\mathrm{L}$ and $\mathrm{M}$, which is fixed to link 6 . Also, when $\mathrm{q}_{1}$ is locked, $\mathrm{D}$ becomes a point of the frame and the points $\mathrm{A}, \mathrm{B}, \mathrm{E}$ and $\mathrm{D}$ become the vertices of the four-bar loop that locates $\mathrm{I}_{71}{ }^{(2)}$ as common intersection between the same line through $\mathrm{A}$ and $\mathrm{B}$ and the line through $\mathrm{D}$ and $\mathrm{E}$, which is fixed to link 4. The coordinates of the points $\mathrm{I}_{71}{ }^{(1)}$ and $\mathrm{I}_{71}{ }^{(2)}$ as a function of the mechanism configuration can be easily determined by solving two linear systems of two equations in two unknowns (see Appendix A and, for the general case, Ref. [21]).

The above discussion demonstrates that, in the studied mechanism, the instant centers $\mathrm{I}_{71}{ }^{(1)}$ and $\mathrm{I}_{71}{ }^{(2)}$ always lie on the line passing through the points A and B, which is fixed to link 2 (Fig. 5). Thus, statement II and its corollary (II.b) indicate this line as the central axis of a force system, applied to link 7 , that can be equilibrated by the passive structure of the mechanism without applying torques in the actuators. Moreover, statement I and Eqs. (13) highlight that, in the studied case, the actual position of $\mathrm{I}_{71}$, which may also be a point at infinity, depends on the ratio between the rates of the two actuated-joint variables and must lie on the same line, since the centroid of two heavy points lies on the line through the two points and depends on the ratio between the two weights. In detail, Eqs. (13a) and (13b), particularized to this case, become

$\omega_{71}\left(\mathbf{I}_{71}-\mathbf{A}\right)=\omega_{71}^{(1)}\left(\mathbf{I}_{71}{ }^{(1)}-\mathbf{A}\right)+\omega_{71}{ }^{(2)}\left(\mathbf{I}_{71}{ }^{(2)}-\mathbf{A}\right)$

$\omega_{71}=\omega_{71}{ }^{(1)}+\omega_{71}^{(2)}=\mathrm{g}_{1} \dot{\mathrm{q}}_{1}+\mathrm{g}_{2} \dot{\mathrm{q}}_{2}$

with $\omega_{71}^{(1)}=\mathrm{g}_{1} \dot{\mathrm{q}}_{1}$ and $\omega_{71}^{(2)}=\mathrm{g}_{2} \dot{\mathrm{q}}_{2}$ where the coefficients $\mathrm{g}_{1}$ and $\mathrm{g}_{2}$ can be easily computed by time differentiating Eqs. (27a) and (27b) and, then, linearly eliminating the passive-joint rate $\dot{\theta}_{21}$ (see Appendix B). Equation (28b) reveals that link 7 can translate along the direction perpendicular to the line through $\mathrm{A}$ and $\mathrm{B}$ (i.e., $\mathrm{I}_{71}$ is the point at infinity along this line and $\omega_{71}=0$ ) with translation velocity ${ }^{1} \boldsymbol{V}_{7}=\omega_{71}{ }^{(2)} \mathbf{k} \times\left(\mathbf{I}_{71}{ }^{(2)}-\mathbf{I}_{\mathrm{rs}}{ }^{(1)}\right)$, iff $\omega_{71}{ }^{(1)}=-\omega_{71}{ }^{(2)}$, that is, iff 
$\frac{\dot{\mathrm{q}}_{1}}{\dot{\mathrm{q}}_{2}}=-\frac{\mathrm{g}_{2}}{\mathrm{~g}_{1}}$

Since the line through the points A and B is fixed to link 2 (Fig. 5) which rotates about point A, the possible finite translation of link 7 can only occur along a circular path with center A.

Moreover, Eqs. (28a) and (28b) can be exploited to make link 7 rotate about a particular point of the line through $\mathrm{A}$ and $\mathrm{B}$. In this regard, the two cases $\mathrm{I}_{71} \equiv \mathrm{A}$ and $\mathrm{I}_{71} \equiv \mathrm{B}$ are of particular interest since point $\mathrm{A}$ is the pivot of the lines that, during the mechanism motion, pass through $\mathrm{I}_{71}{ }^{(1)}$ and $\mathrm{I}_{71}{ }^{(2)}$ and point $\mathrm{B}$ is the center of the R pair that joins links 7 and 2.

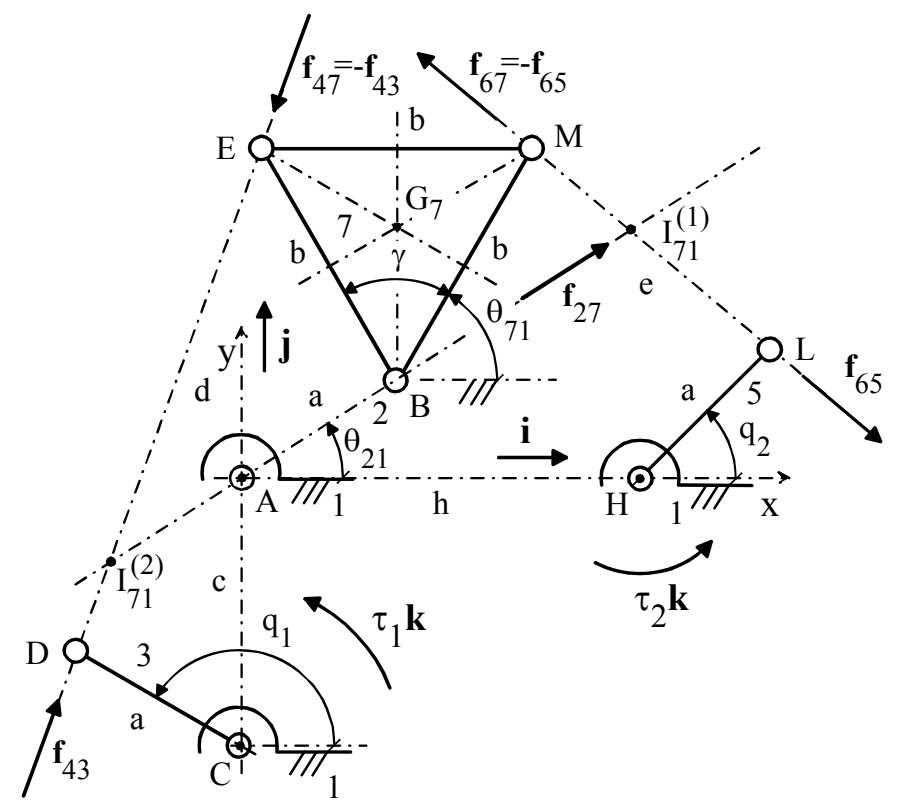

Figure 6: Statics of the 2 RRR-RR mechanism (the inertia forces of the binary links are neglected): $\mathbf{f}_{27}, \mathbf{f}_{47}$ and $f_{67}$ are the constraint forces applied to link $7 ; \tau_{1} k$ and $\tau_{2} k$ are the torques applied by the actuators to links 3 and 5, respectively.

If $\mathrm{I}_{71} \equiv \mathrm{A}$, links 2 and 7 instantaneously rotate as a unique link (i.e., the $\mathrm{R}$ pair centered at $\mathrm{B}$ is idle). The introduction of this condition into Eq. (28a) yields the relationship

$\left(\mathbf{I}_{71}^{(1)}-\mathbf{A}\right) \mathrm{g}_{1} \dot{\mathrm{q}}_{1}+\left(\mathbf{I}_{71}{ }^{(2)}-\mathbf{A}\right) \mathrm{g}_{2} \dot{\mathrm{q}}_{2}=\mathbf{0}$

whose dot product by $(\mathbf{B}-\mathbf{A})$ gives the following condition on the ratio of the actuated-joint rates 
$\frac{\dot{\mathrm{q}}_{1}}{\dot{\mathrm{q}}_{2}}=-\frac{\mathrm{g}_{2}\left(\mathbf{I}_{71}{ }^{(2)}-\mathbf{A}\right) \cdot(\mathbf{B}-\mathbf{A})}{\mathrm{g}_{1}\left(\mathbf{I}_{71}{ }^{(1)}-\mathbf{A}\right) \cdot(\mathbf{B}-\mathbf{A})}$

If $\mathrm{I}_{71} \equiv \mathrm{B}$, links 2 is at rest and keeps point $\mathrm{B}$ at rest while link 7 instantaneously rotates. The introduction of this condition into Eqs. (28) yields, after some rearrangements, the relationship

$\left(\mathbf{I}_{71}{ }^{(1)}-\mathbf{B}\right) \mathrm{g}_{1} \dot{\mathrm{q}}_{1}+\left(\mathbf{I}_{71}{ }^{(2)}-\mathbf{B}\right) \mathrm{g}_{2} \dot{\mathrm{q}}_{2}=\mathbf{0}$

whose dot product by $(\mathbf{B}-\mathbf{A})$ gives the following condition on the ratio of the actuated-joint rates

$\frac{\dot{\mathrm{q}}_{1}}{\dot{\mathrm{q}}_{2}}=-\frac{\mathrm{g}_{2}\left(\mathbf{I}_{71}{ }^{(2)}-\mathbf{B}\right) \cdot(\mathbf{B}-\mathbf{A})}{\mathrm{g}_{1}\left(\mathbf{I}_{71}{ }^{(1)}-\mathbf{B}\right) \cdot(\mathbf{B}-\mathbf{A})}$

Since point A is fixed to the frame and the line through A and B does not change its orientation when B is at rest, conditions (31) or (33) can be exploited to obtain also finite rotations of link 7 around A or around an assigned point of the circular path of point $\mathrm{B}$.

All the expressions at the right-hand side of Eqs. (29), (31) and (33) can be analytically computed as a function of the mechanism configuration (i.e., as a function of $\mathrm{q}_{1}$ and $\mathrm{q}_{2}$ ). They can be exploited at the design stage to suitably size the mechanism according to a specific task; whereas, Eqs. (29) or (31) or (33) are automatically satisfied when $\mathrm{q}_{1}$ and $\mathrm{q}_{2}$ as a function of time have been computed through the IPA by imposing that link 7 performs either a finite translation or a finite rotation about A or B to link 7 .

The fact that the studied mechanism can make link 7 either translate along a circular path or rotate around A or B reveals that this mechanism with all the actuators on the frame is a good alternative to the serial $\underline{\mathrm{RR}}$ one.

\subsection{Dynamic Model}

Figure 6 shows the constraint forces $\mathbf{f}_{27}, \mathbf{f}_{47}$ and $\mathbf{f}_{67}$ applied to link 7 and the torques $\tau_{1} \mathbf{k}$ and $\tau_{2} \mathbf{k}$ applied to links 3 and 5, respectively, by the actuators under the hypothesis that the inertia forces of the binary links are negligible. $\mathbf{f}_{27}, \mathbf{f}_{47}$ and $\mathbf{f}_{67}$ can be analytically expressed as follows:

$\mathbf{f}_{27}=\mathrm{f}_{27} \frac{(\mathbf{B}-\mathbf{A})}{\mathrm{a}}=\mathrm{f}_{27}\left(\cos \theta_{21} \mathbf{i}+\sin \theta_{21} \mathbf{j}\right)$ 


$$
\begin{aligned}
\mathbf{f}_{47}=\mathrm{f}_{47} \frac{(\mathbf{D}-\mathbf{E})}{\mathrm{d}}= & -\mathrm{f}_{47}\left\{\left[(\mathrm{a} / \mathrm{d})\left(\cos \theta_{21}-\cos q_{1}\right)+(\mathrm{b} / \mathrm{d}) \cos \left(\theta_{71}+\gamma\right)\right] \mathbf{i}+\right. \\
& {\left.\left[(\mathrm{a} / \mathrm{d})\left(\sin \theta_{21}-\sin q_{1}\right)+(\mathrm{b} / \mathrm{d}) \sin \left(\theta_{71}+\gamma\right)+(\mathrm{c} / \mathrm{d})\right] \mathbf{j}\right\} }
\end{aligned}
$$

$\mathbf{f}_{67}=\mathrm{f}_{67} \frac{(\mathbf{M}-\mathbf{L})}{\mathrm{e}}=\mathrm{f}_{67}\left\{\left[(\mathrm{a} / \mathrm{e})\left(\cos \theta_{21}-\cos q_{2}\right)+(\mathrm{b} / \mathrm{e}) \cos \theta_{71}-(\mathrm{h} / \mathrm{e})\right] \mathbf{i}+\left[(\mathrm{a} / \mathrm{e})\left(\sin \theta_{21}-\sin q_{2}\right)+(\mathrm{b} / \mathrm{e}) \sin \theta_{71}\right] \mathbf{j}\right\}$

where $f_{27}, f_{47}$ and $f_{67}$ are the signed magnitudes of $\mathbf{f}_{27}, \mathbf{f}_{47}$ and $\mathbf{f}_{67}$, respectively. Also, the moment equilibriums of links 3 and 5 yields

$$
\begin{aligned}
& \mathrm{f}_{47}=\frac{\mathrm{d}}{\mathbf{k} \cdot(\mathbf{D}-\mathbf{C}) \times(\mathbf{E}-\mathbf{D})} \tau_{1} \\
& \mathrm{f}_{67}=\frac{\mathrm{e}}{\mathbf{k} \cdot(\mathbf{L}-\mathbf{H}) \times(\mathbf{L}-\mathbf{M})} \tau_{2}
\end{aligned}
$$

The corresponding planar wrenches about $\mathrm{A}$ are

$$
\begin{aligned}
& \$_{\mathrm{A} \mid 2,7}=\mathrm{f}_{27} \frac{(\mathbf{B}-\mathbf{A})}{\mathrm{a}}=\mathrm{f}_{27} \sigma_{\mathrm{A} \mid 2,7} \\
& \$_{\mathrm{A} \mid 4,7}=\tau_{1} \frac{\mathrm{d}}{\mathbf{k} \cdot(\mathbf{D}-\mathbf{C}) \times(\mathbf{E}-\mathbf{D})} \sigma_{\mathrm{A} \mid 4,7} \\
& \$_{\mathrm{A} \mid 6,7}=\tau_{2} \frac{\mathrm{e}}{\mathbf{k} \cdot(\mathbf{L}-\mathbf{H}) \times(\mathbf{L}-\mathbf{M})} \sigma_{\mathrm{A} \mid 6,7}
\end{aligned}
$$

where the unit planar wrenches $\sigma_{\mathrm{A} \mid 2,7}, \sigma_{\mathrm{A} \mid 4,7}$ and $\sigma_{\mathrm{A} \mid 6,7}$ have the following explicit expressions

$$
\boldsymbol{\sigma}_{\mathrm{A} \mid 2,7}=\left(\cos \theta_{21} \mathbf{i}+\sin \theta_{21} \mathbf{j}\right)
$$

$$
\begin{aligned}
\sigma_{\mathrm{A} \mid 4,7}= & \frac{1}{\mathrm{~d}}\{(\mathbf{D}-\mathbf{E})+[\mathbf{k} \cdot(\mathbf{E}-\mathbf{A}) \times(\mathbf{D}-\mathbf{E})] \mathbf{k}\}=\left[(\mathrm{a} / \mathrm{d})\left(\cos q_{1}-\cos \theta_{21}\right)-(\mathrm{b} / \mathrm{d}) \cos \left(\theta_{71}+\gamma\right)\right] \mathbf{i}+ \\
& {\left.\left[(\mathrm{a} / \mathrm{d})\left(\sin q_{1-}-\sin \theta_{21}\right)-(\mathrm{b} / \mathrm{d}) \sin \left(\theta_{71}+\gamma\right)-(\mathrm{c} / \mathrm{d})\right)\right] \mathbf{j}+\left\{[ \mathrm { a } \operatorname { c o s } \theta _ { 2 1 } + \mathrm { b } \operatorname { c o s } ( \theta _ { 7 1 } + \gamma ) ] \left[(\mathrm{a} / \mathrm{d})\left(\sin q_{1}-\sin \theta_{21}\right)-\right.\right.} \\
& \left.\left.\left.(\mathrm{b} / \mathrm{d}) \sin \left(\theta_{71}+\gamma\right)-(\mathrm{c} / \mathrm{d})\right)\right]-\left[\mathrm{a} \sin \theta_{21}+\mathrm{b} \sin \left(\theta_{71}+\gamma\right)\right]\left[(\mathrm{a} / \mathrm{d})\left(\cos q_{1}-\cos \theta_{21}\right)-(\mathrm{b} / \mathrm{d}) \cos \left(\theta_{71}+\gamma\right)\right]\right\} \mathbf{k}
\end{aligned}
$$




$$
\begin{aligned}
\sigma_{\mathrm{A} \mid 6,7}= & \frac{1}{\mathrm{e}}\{(\mathbf{M}-\mathbf{L})+[\mathbf{k} \cdot(\mathbf{M}-\mathbf{A}) \times(\mathbf{M}-\mathbf{L})] \mathbf{k}\}=\left[(\mathrm{a} / \mathrm{e})\left(\cos \theta_{21}-\cos q_{2}\right)+(\mathrm{b} / \mathrm{e}) \cos \theta_{71}-(\mathrm{h} / \mathrm{e})\right] \mathbf{i}+ \\
& {\left[(\mathrm{a} / \mathrm{e})\left(\sin \theta_{21}-\sin q_{2}\right)+(\mathrm{b} / \mathrm{e}) \sin \theta_{71}\right] \mathbf{j}+\left\{( \mathrm { a } \operatorname { c o s } \theta _ { 2 1 } + \mathrm { b } \operatorname { c o s } \theta _ { 7 1 } ) \left[(\mathrm{a} / \mathrm{e})\left(\sin \theta_{21}-\sin q_{2}\right)+\right.\right.} \\
& \left.\left.(\mathrm{b} / \mathrm{e}) \sin \theta_{71}\right]-\left(\mathrm{a} \sin \theta_{21}+\mathrm{b} \sin \theta_{71}\right)\left[(\mathrm{a} / \mathrm{e})\left(\cos \theta_{21}-\cos q_{2}\right)+(\mathrm{b} / \mathrm{e}) \cos \theta_{71}-(\mathrm{h} / \mathrm{e})\right]\right\} \mathbf{k}
\end{aligned}
$$

Also, the effective-acceleration vector of link 7 referred to point $\mathrm{A}$ is

${ }^{1} \chi_{\mathrm{A} \mid 7, \mathrm{ef}}={ }^{1} \mathbf{a}_{\mathrm{G} \mid 7}+\left[\mathbf{k} \cdot\left(\mathbf{G}_{7}-\mathbf{A}\right) \times{ }^{1} \mathbf{a}_{\mathrm{G} \mid 7}+\delta_{7}{ }^{2} \alpha_{71}\right] \mathbf{k}$

and the external wrench about $\mathrm{A}, \$_{\mathrm{A} \mid 7, \mathrm{ex}}$, applied to link 7 can be written as follows

$$
\mathbf{S}_{\mathrm{A} \mid 7, \mathrm{ex}}=\mathrm{f}_{\mathrm{ex}} \sigma_{\mathrm{A} \mid 7, \mathrm{ex}}
$$

The introduction of Eqs. (36), (38) and (39) into Eq. (21b) yields the following dynamic model of the studied mechanism

$\mathrm{f}_{\mathrm{ex}} \sigma_{\mathrm{A} \mid 7, \mathrm{ex}}+\mathrm{f}_{27} \sigma_{\mathrm{A} \mid 2,7}+\tau_{1} \frac{\mathrm{d}}{\mathbf{k} \cdot(\mathbf{D}-\mathbf{C}) \times(\mathbf{E}-\mathbf{D})} \sigma_{\mathrm{A} \mid 4,7}+\tau_{2} \frac{\mathrm{e}}{\mathbf{k} \cdot(\mathbf{L}-\mathbf{H}) \times(\mathbf{L}-\mathbf{M})} \sigma_{\mathrm{A} \mid 6,7}=\mu_{7}{ }^{1} \chi_{\mathrm{A} \mid 7, \mathrm{ef}}$

Eventually, the dot product of Eq. (40) by $\sigma_{\mathrm{A} \mid 2,7} \times \sigma_{\mathrm{A} \mid 6,7}$ and of Eq. (40) by $\sigma_{\mathrm{A} \mid 2,7} \times \sigma_{\mathrm{A} \mid 4,7}$ straightforwardly yields the following explicit solution of the inverse dynamics problem

$$
\begin{gathered}
\tau_{1}=\frac{[\mathbf{k} \cdot(\mathbf{D}-\mathbf{C}) \times(\mathbf{E}-\mathbf{D})]\left(\mu_{7}{ }^{1} \chi_{\mathrm{A} \mid 7, \mathrm{ef}}-\mathrm{f}_{\mathrm{ex}} \boldsymbol{\sigma}_{\mathrm{A} \mid 7, \mathrm{ex}}\right) \cdot \boldsymbol{\sigma}_{\mathrm{A} \mid 2,7} \times \boldsymbol{\sigma}_{\mathrm{A} \mid 6,7}}{\mathrm{~d} \boldsymbol{\sigma}_{\mathrm{A} \mid 4,7} \cdot \boldsymbol{\sigma}_{\mathrm{A} \mid 2,7} \times \boldsymbol{\sigma}_{\mathrm{A} \mid 6,7}} \\
\tau_{2}=\frac{[\mathbf{k} \cdot(\mathbf{L}-\mathbf{H}) \times(\mathbf{L}-\mathbf{M})]\left(\mu_{7}{ }^{1} \chi_{\mathrm{A} \mid 7, \mathrm{ef}}-\mathrm{f}_{\mathrm{ex}} \boldsymbol{\sigma}_{\mathrm{A} \mid 7, \mathrm{ex}}\right) \cdot \boldsymbol{\sigma}_{\mathrm{A} \mid 2,7} \times \boldsymbol{\sigma}_{\mathrm{A} \mid 4,7}}{\mathrm{e} \boldsymbol{\sigma}_{\mathrm{A} \mid 6,7} \cdot \boldsymbol{\sigma}_{\mathrm{A} \mid 2,7} \times \boldsymbol{\sigma}_{\mathrm{A} \mid 4,7}}
\end{gathered}
$$




\section{Conclusions}

In planar motion, rigid-body's (link's) configuration space (c-space) is a three-dimensional space which can be equipped with the structure of an affine space. Here, this structure has been introduced by using three-dimensional vectors (planar-pose vectors) with non-homogeneous components.

The proposed affine structure of link's c-space has been exploited to provide tools useful to study link's planar motion as the motion of a c-space point. Also, these tools combined with the planar wrenches have revealed, in a simple and direct way, the role of instant centers in planar mechanisms' statics.

Eventually, planar wrenches together with the proposed tools made it possible the formulation of the "motion laws" of the c-space point and the study of planar mechanisms' dynamics as a number of c-space points that interact one another and stand external planar wrenches.

The result is a coherent, autonomous and self-contained set of tools and laws that model kinematics and dynamics of planar mechanisms in the three-dimensional configuration space of links' planar poses.

A two-dof parallel planar mechanism has been studied by using some of the found results. This case study clearly shows how visible the kinematic behaviour of a mechanism becomes with these new tools.

\section{Acknowledgments}

This work has been developed at the Laboratory of Advanced Mechanics (MECH-LAV) of Ferrara Technopole, supported by UNIFE and MIUR funds and by Regione Emilia Romagna (District Councillorship for Productive Assets, Economic Development, Telematic Plan) POR-FESR 2007-2013, Attività I.1.1.

\section{Appendix A}

The following vector equations can be written (see Fig. 5)

$$
\begin{aligned}
& \left(\mathbf{I}_{71}{ }^{(1)}-\mathbf{A}\right)=\mathrm{w}_{1}(\mathbf{B}-\mathbf{A}) \\
& \left(\mathbf{I}_{71}{ }^{(1)}-\mathbf{A}\right)=\mathrm{w}_{2}(\mathbf{M}-\mathbf{L})+(\mathbf{L}-\mathbf{A}) \\
& \left(\mathbf{I}_{71}{ }^{(2)}-\mathbf{A}\right)=\mathrm{w}_{3}(\mathbf{B}-\mathbf{A}) \\
& \left(\mathbf{I}_{71}{ }^{(2)}-\mathbf{A}\right)=\mathrm{w}_{4}(\mathbf{E}-\mathbf{D})+(\mathbf{D}-\mathbf{A})
\end{aligned}
$$


where the scalar coefficients $\mathrm{w}_{\mathrm{j}}$, for $\mathrm{j}=1, \ldots, 4$, are unknowns to be determined; whereas, the explicit expressions of (B-A), $(\mathbf{L}-\mathbf{A})$ and $(\mathbf{D}-\mathbf{A})$ are given by Eqs. (25) and those of $(\mathbf{M}-\mathbf{L})$ and $(\mathbf{E}-\mathbf{D})$ by Eqs. (26).

The linear elimination of $\left(\mathbf{I}_{71}{ }^{(1)}-\mathbf{A}\right)$ and $\left(\mathbf{I}_{71}{ }^{(2)}-\mathbf{A}\right)$ from Eqs. (A1) yields the following two vector equations

$\mathrm{w}_{1}(\mathbf{B}-\mathbf{A})-\mathrm{w}_{2}(\mathbf{M}-\mathbf{L})=(\mathbf{L}-\mathbf{A})$

$\mathrm{w}_{3}(\mathbf{B}-\mathbf{A})-\mathrm{w}_{4}(\mathbf{E}-\mathbf{D})=(\mathbf{D}-\mathbf{A})$

which are two linear systems of two scalar equations in two unknowns whose solution is

$$
\begin{aligned}
& \mathrm{w}_{1}=\frac{(\mathbf{L}-\mathbf{A}) \cdot[\mathbf{k} \times(\mathbf{M}-\mathbf{L})]}{(\mathbf{B}-\mathbf{A}) \cdot[\mathbf{k} \times(\mathbf{M}-\mathbf{L})]} \\
& \mathrm{w}_{2}=-\frac{(\mathbf{L}-\mathbf{A}) \cdot[\mathbf{k} \times(\mathbf{B}-\mathbf{A})]}{(\mathbf{M}-\mathbf{L}) \cdot[\mathbf{k} \times(\mathbf{B}-\mathbf{A})]} \\
& \mathrm{w}_{3}=\frac{(\mathbf{D}-\mathbf{A}) \cdot[\mathbf{k} \times(\mathbf{E}-\mathbf{D})]}{(\mathbf{B}-\mathbf{A}) \cdot[\mathbf{k} \times(\mathbf{E}-\mathbf{D})]} \\
& \mathrm{w}_{4}=-\frac{(\mathbf{D}-\mathbf{A}) \cdot[\mathbf{k} \times(\mathbf{B}-\mathbf{A})]}{(\mathbf{E}-\mathbf{D}) \cdot[\mathbf{k} \times(\mathbf{B}-\mathbf{A})]}
\end{aligned}
$$

Formulas (A3) provide the explicit expressions of the scalar coefficients $w_{j}$, for $j=1, \ldots, 4$, as a function of the mechanism configuration. Eventually, the introduction of such expressions into Eqs. (A1) yields the explicit expressions of $\left(\mathbf{I}_{71}^{(1)}-\mathbf{A}\right)$ and $\left(\mathbf{I}_{71}^{(2)}-\mathbf{A}\right)$ as a function of the mechanism configuration.

\section{Appendix B}

The time derivative of Eqs. (27a) and (27b) yields

$$
\begin{aligned}
& \mathrm{n}_{11} \dot{\theta}_{21}+\mathrm{n}_{12} \omega_{71}+\mathrm{n}_{13} \dot{\mathrm{q}}_{1}=0 \\
& \mathrm{n}_{21} \dot{\theta}_{21}+\mathrm{n}_{22} \omega_{71}+\mathrm{n}_{23} \dot{\mathrm{q}}_{2}=0
\end{aligned}
$$

where

$\mathrm{n}_{11}=\mathrm{ab}\left[\sin \left(\theta_{71}+\gamma\right) \cos \theta_{21}-\cos \left(\theta_{71}+\gamma\right) \sin \theta_{21}\right]-\mathrm{a}^{2}\left(\cos \theta_{21} \sin q_{1}-\sin \theta_{21} \cos q_{1}\right)+\mathrm{ca} \cos \theta_{21}$ 


$$
\begin{aligned}
& \mathrm{n}_{12}=a b\left[\cos \left(\theta_{71}+\gamma\right)\left(\sin \theta_{21}-\sin q_{1}\right)-\sin \left(\theta_{71}+\gamma\right)\left(\cos \theta_{21}-\cos q_{1}\right)\right]+\operatorname{cb} \cos \left(\theta_{71}+\gamma\right) \\
& \mathrm{n}_{13}=a b\left[\sin q_{1} \cos \left(\theta_{71}+\gamma\right)-\cos q_{1} \sin \left(\theta_{71}+\gamma\right)\right]-\mathrm{a}^{2}\left(\sin \theta_{21} \cos q_{1}-\cos \theta_{21} \sin q_{1}\right)-\operatorname{ca} \cos q_{1} \\
& \mathrm{n}_{21}=a b\left(\sin \theta_{71} \cos \theta_{21}-\cos \theta_{71} \sin \theta_{21}\right)-\mathrm{a}^{2}\left(\cos \theta_{21} \sin q_{2}-\sin \theta_{21} \cos q_{2}\right)+\text { ha } \sin \theta_{21} \\
& \mathrm{n}_{22}=a b\left[\cos \theta_{71}\left(\sin \theta_{21}-\sin q_{2}\right)-\sin \theta_{71}\left(\cos \theta_{21}-\cos q_{2}\right)\right]+\text { hb } \sin \theta_{71} \\
& \mathrm{n}_{23}=a b\left(\cos \theta_{71} \sin q_{2}-\sin \theta_{71} \cos q_{2}\right)-\mathrm{a}^{2}\left(\sin \theta_{21} \cos q_{2}-\cos \theta_{21} \sin q_{2}\right)-\text { ha } \sin q_{2}
\end{aligned}
$$

The subtraction of the product of Eq. (B1a) by $n_{21}$ from the product of Eq. (B1b) by $n_{11}$ yields

$\left(\mathrm{n}_{22} \mathrm{n}_{11}-\mathrm{n}_{21} \mathrm{n}_{12}\right) \omega_{71}=\mathrm{n}_{21} \mathrm{n}_{13} \dot{\mathrm{q}}_{1}-\mathrm{n}_{23} \mathrm{n}_{11} \dot{\mathrm{q}}_{2}$

whose comparison with Eq. (28b) gives, for $g_{1}$ and $g_{2}$, the following explicit expressions as a function of the mechanism configuration

$$
\begin{aligned}
& \mathrm{g}_{1}=\frac{\mathrm{n}_{21} \mathrm{n}_{13}}{\mathrm{n}_{22} \mathrm{n}_{11}-\mathrm{n}_{21} \mathrm{n}_{12}} \\
& \mathrm{~g}_{2}=\frac{\mathrm{n}_{23} \mathrm{n}_{11}}{\mathrm{n}_{21} \mathrm{n}_{12}-\mathrm{n}_{22} \mathrm{n}_{11}}
\end{aligned}
$$

\section{References}

[1] Paul B., (1979), "Kinematics and dynamics of planar machinery," Prentice-Hall, Inc., Englewood Cliffs, New Jersey (USA).

[2] Mason M., (2001), “Mechanics of robotic manipulation,” MIT Press, Cambridge, MA (USA).

[3] Lounesto, P., (2004), "Introduction to Clifford Algebras," in: Lectures on Clifford (Geometric) Algebras and Applications, Ablamowicz R. et al. (eds.), Springer Science+Business Media, New York (USA), pp. 1-30.

[4] Hervé J.M., (1994), "The mathematical group structure of the set of displacements," Mechanism and Machine Theory 29 (1) 73-81.

[5] Bonev I.A., Zlatanov D., Gosselin C. M., (2003), "Singularity Analysis of 3-DOF Planar Parallel Mechanisms via Screw Theory," ASME J. of Mechanical Design, 125 (3) 573-581.

[6] Reuleaux F., (1876),“The kinematics of machinery,” MacMillan and Co., London, UK.

[7] Lin Q., Burdick J., (2000), "Objective and frame-invariant kinematic metric functions for rigid bodies," The International Journal of Robotics Research, 19(6) 612-625.

[8] Di Gregorio R., (2008), "A novel point of view to define the distance between two rigid-body poses," in: Advances in Robot Kinematics: Analysis and Design, ARK2008, Eds. J. Lenarcic and P. Wenger, Springer Scince + Business Media Publishers, Amsterdam (the Netherlands), ISBN: 978-1-40208599-4, pp. 361-369. 
[9] Di Gregorio R., (2009), "Review and comparison of the metrics proposed for measuring the distance between two rigid-body poses," in: Seconda Giornata di Studio Ettore Funaioli: 18 luglio 2008, Meneghetti U., Maggiore A. and Parenti-Castelli V. (Eds.), Quaderni del DIEM, Bologna, ISBN: 97888-86909-53-2, DOI: 10.6092/unibo/amsacta/2552, pp. 221-233.

[10] Tenenbaum R.A., (2004), “Fundamentals of applied dynamics,” Springer, New York (USA).

[11] Di Gregorio R., (2009), "A novel method for the singularity analysis of planar mechanisms with more than one degree of freedom," Mechanism and Machine Theory 44 (1) 83-102.

[12] Newton I., (1687), "Philosophiæ Naturalis Principia Mathematica,” S. Pepys, Reg. Soc. præses, London (UK).

[13] Pennock G.R., Israr A., (2009), "Kinematic analysis and synthesis of an adjustable six-bar linkare," Mechanism and Machine Theory 44 (2) 306-323.

[14] Hunt K.H., (1983), "Structural Kinematics of In-Parallel-Actuated Robot-Arms," ASME J. of Mechanisms, Transmissions, and Automation in Design, 105 (4) 705-712.

[15] Gosselin C.M., Sefrioui J, (1991), "Polynomial Solutions for the Direct Kinematic Problem of Planar Three-Degree-of-Freedom Parallel Manipulator," in: Proc. of the 1991 International Conference on Advanced Robotics, Pisa, Italy. pp. 1121-1129.

[16] Tsai L.-W., (1999), "Robot Analysis: The Mechanics of Serial and Parallel Manipulators," John Wiley \& Sons, Inc., New York (USA).

[17] Primrose E.J.F., Freudenstein F., Roth B., (1967), "Six-bar motion," Archive for Rational Mechanics and Analysis, 24(1) 22-77.

[18] Watanabe K., Funabashi H., (1984), "Kinematic analysis of Stephenson six-link mechanisms," Bulletin of the Japan Society of Mechanical Engineers, 27 (234) 2863-2878.

[19] Watanabe K., Katoh H., (2004), "Identification of motion domains of planar six-link mechanisms of the Stephenson-type,” Mechanism and Machine Theory, 39 (10) 1081-1099.

[20] Simionescu P.A., Smith M.R., (2001), "Four- and six-bar function cognates and overconstrained mechanisms," Mechanism and Machine Theory, 36 (8) 913-924.

[21] Di Gregorio R., (2008), “An Algorithm for Analytically Calculating the Positions of the Secondary Instant Centers of Indeterminate Linkages," ASME J. of Mechanical Design, 130(4) 042303-(1:9). 